\title{
Extraction of laminarin from Saccharina latissima seaweed using cross-flow filtration
}

\author{
Martin Sterner $^{1}$ (D) $\cdot$ Fredrik Gröndahl $^{1}$ [D \\ Received: 22 October 2020 / Revised and accepted: 14 January 2021 / Published online: 22 February 2021 \\ (C) The Author(s) 2021
}

\begin{abstract}
Laminarin is a low-molecular-weight polysaccharide found in seaweed (kelp), often in equal concentrations to that in the commercially important hydrocolloid alginate. However, while alginate can be easily recovered by dissolution followed by acid precipitation, for laminarin, there is no such straightforward way of recovering it. Laminarin can be used as dietary fiber and, if efficiently extracted, it may be used for functional food/feed applications and as a component in plant defense stimulants for agriculture. One way of concentrating laminarin from dilute solutions is to press the solution through ultrafine membranes that the molecules cannot pass through. When alginate is extracted, an acid pretreatment step is used and the dilute acid residue from that process also contains laminarin. We used cross-flow filtration to concentrate laminarin from Saccharina latissima, retrieving it from the dilute acid solution of the acid pretreatment of an alginate extraction. Three ceramic membranes with 5,15 , and $50 \mathrm{kDa}$ molecular weight cutoffs were used, and the pressure, temperature, and feed velocity were altered to reveal which parameters controlled the flow through the membrane and how efficiently laminarin was concentrated. The effects on laminarin extraction for fresh vs. frozen biomass were evaluated showing that frozen biomass releases more laminarin with a similar biomass homogenization technique. Thermal and microbial degradation of the feed components was studied during the course of the filtrations, showing that microbial degradation can affect the laminarin concentration, while the temperature of the process $\sim 65$ ${ }^{\circ} \mathrm{C}$ had little impact on laminarin. The techniques used to monitor the components in the feed and permeate during filtration were nuclear magnetic resonance, ${ }^{1} \mathrm{H}-\mathrm{NMR}$, and size exclusion chromatography. The filtrations were performed in a pilot-size filtration unit with ceramic membranes $\left(\mathrm{ZrO}_{2} / \mathrm{TiO}_{2}, \mathrm{TiO}_{2}-\mathrm{Al}_{2} \mathrm{O}\right.$ support, $\left.0.08 \mathrm{~m}^{2}\right)$. To be able to operate without quick membrane fouling, the most important parameter was to have a high liquid velocity over the membrane, $4.7 \mathrm{~m} \mathrm{~s}^{-1}$. A good technique to concentrate laminarin was to prefilter it through a 50-kDa membrane using 2 bar liquid pressure and to concentrate it over a 5$\mathrm{kDa}$ membrane using 5-bar liquid pressure. With these settings, the liquid flux through the filter became 60-80 and 30-40 $\mathrm{L} \mathrm{m}^{-2} \mathrm{~h}^{-1}$ over the 50-kDa and 5-kDa membrane.
\end{abstract}

Keywords Cross-flow filtration $\cdot$ Laminarin $\cdot$ Mannitol $\cdot$ Saccharina latissima $\cdot$ Kelp $\cdot$ Extraction

\section{Introduction}

Mariculture of seaweed (kelp) has the potential to generate large volumes of new biomass. Seaweed cultivation at sea requires no fertilization, irrigation, or maintenance during its growth, and the production can give a high yield per cultivated area in a highly sustainable way (Thomas et al. 2020).

Martin Sterner

msterne@kth.se

1 SEED, Department of Sustainable Development, Environmental Science and Engineering, ABE, School of Architecture and the Built Environment, KTH, Royal Institute of Technology, Stockholm, Sweden
One species of seaweed that is suitable for farming in cold saline water is Saccharina latissima, a brown alga in the order Laminariales. It grows at a rapid pace and thrives on the Swedish west coast where it is cultivated but also grows wild. Seaweed cultivation in Sweden has been developed in two research projects called "Seafarm" and "Agri Aqua Kelp" during 2014-2020, but from 2020 on, seaweed farming has become commercial via a startup company (KosterAlg). An average yearly harvest of $19 \mathrm{t} \mathrm{ha}^{-1}$ is achieved for the KosterAlg cultivation (Hasselström et al. 2020). It has also been estimated that it is possible to sequester more $\mathrm{CO}_{2}$ in the seaweed than the total $\mathrm{CO}_{2}$ equivalents required for cultivation and preservation (Thomas et al. 2020).

Since $S$. latissima contains more than one utilizable component, it can be advantageous to find ways to extract these 
components in sequence and enable the use of a greater share of the biomass (Sterner and Edlund 2016; Sterner et al. 2017).

The main components in S. latissima are laminarin $\sim 7-$ $40 \%$, alginate $\sim 15-35 \%$, mannitol $\sim 10-15 \%$, protein $\sim 4$ $13 \%$, and cellulose $\sim 5-15 \%$ (Obluchinskaya 2008; Jard et al. 2013; Schiener et al. 2015; Vilg et al. 2015; Sterner and Edlund 2016; Sterner et al. 2017; Stévant et al. 2017). The share of algal components varies between years and seasons and by the local growth conditions.

Laminarin is the primary energy reserve of the seaweed that is built up during spring and summer to be spent during the winter (Schiener et al. 2015; Vilg et al. 2015). It is a lowmolecular-weight $\left(\mathrm{M}_{\mathrm{w}}\right)$ polysaccharide that usually has a $\mathrm{M}_{\mathrm{w}}$ of 3-5 kDa and consists of glucose units joined mainly by 1,3beta bonds alternated with a low amount of 1,6-beta bonds, with some 1,6-beta bound branches of single glucose units (Rinaudo 2007). Laminarin can be used as dietary fiber, as a stimulant of the innate immune system of mammals, and as a plant pathogen defense stimulant, the first application, since it is not digested by the human small intestine enzymes and the two later applications due to the resemblance of the laminarin glucose 1,3-beta-bond motif to that of certain fungal polysaccharides to which plants and mammals respond. (Yvin et al. 1998; Klarzynski et al. 2000; Aziz et al. 2003; Brown and Williams 2009; Myklestad and Granum 2009; McDonnell et al. 2010). Alginate is a high- $M_{w}$ linear charged polysaccharide consisting of two alternating uronic acids, mannuronic acid, and guluronic acid (Rinaudo 2007). It is extracted for its use as a viscosity modifier, gel material, or texturizer in a vast range of products, including food cosmetics and medical products (Draget et al. 2005; Rinaudo 2014; Porse and Rudolph 2017). Mannitol is a sugar alcohol that regulates the osmotic balance in seaweed and can be used as a sweetener similar to xylitol and sorbitol (Pawel 2014).

While alginate can be solubilized in the extraction process and later retrieved again by precipitation with acid, this is not possible for laminarin (Black et al. 1951; McHugh 2003). Laminarin is soluble in water at all $\mathrm{pH}$ values, and it cannot be precipitated without the addition of a high amount of precipitant, such as ethanol or acetone at more than $60 \%$ by weight (Black et al. 1951; Sterner and Edlund 2016). A common technique used to extract alginate is to pretreat the seaweed with dilute acid to leach out calcium ions, which makes it easier to dissolve the alginate at a later stage (McHugh 2003). When using acid pretreatment in the alginate extraction process, if laminarin follows the dilute acid leaching solution, this may allow a combined process to extract both compounds and possibly make the extraction of laminarin easy enough to enable commercial applications.

A way to concentrate laminarin is to use membrane filtration that can separate laminarin according to the size of the molecule (Yvin et al. 1998). One such technique is cross-flow filtration, in which the solution to be filtered (feed) flows at high velocity over the membrane, so that small molecules follow through the membrane with the solution as it goes through (permeate), and the constant high flow hinders the buildup of a filter cake that limits the flux through the membrane (Bhave 1996). For ultrafiltration, the thin layer of ultrafine particles and large molecules that precipitate in a gel-like manner close to the membrane is referred to as "the gel layer," but more generally, it is called the "concentration polarization layer" (Bhave 1996; Ripperger et al. 2013).

To have a successful cross-flow filtration, a setting needs to be found to maximize the liquid volume going through the membrane per unit of time (flux), not only at the start of the filtration but also in a longer time perspective by minimizing the gradual clogging of the membrane (membrane fouling).

If the solution is pressed through the membrane under high pressure, the initial flux is increased, but this triggers the formation of a thicker gel layer and, eventually, more membrane fouling, which soon decreases the flux again. To decrease the thickness of the gel layer, the feed velocity can be increased, but this requires a more powerful pump and generates a greater pressure drop in the membrane filter channels, which allows shorter filters in the filtration setup.

Choosing a membrane with a higher $\mathrm{M}_{\mathrm{w}}$ cutoff and thus larger pores allows for a greater flux, but it cannot allow a great share of the targeted compound to pass through the filter (passage ratio). The passage ratio, which is the share of the targeted compound that goes through the filter, is the opposite of the retention ratio or retention, which is the share of the targeted compound that does not go through the filter. The real membrane cutoff also depends on the thickness and nature of the formed gel layer, and therefore, the cutoff also depends on the feed velocity and pressure in the filtration (Ripperger et al. 2013).

The general theories on cross-flow filtration indicate which factors can affect the performance, but in the end, every kind of feed is unique, and it is hard to predict, for instance, the permeability of the gel layer and the progression of membrane fouling without real testing. Cross-flow filtration has been used as a method for the separation of laminarin before (Yvin et al. 1998), but we found no study that has examined which filtration settings should be used.

The aim of this work was to investigate which cross-flow filtration settings, in the concentration of laminarin from the solution from acid pretreatment of homogenized S. latissima, that lead to fast filtration with high yields. The explored parameters were the feed velocity and pressure over the membranes, choice of membrane $M_{w}$ cutoff, time of filtration, temperature, and effect of prefiltering with a membrane with a higher $\mathrm{M}_{\mathrm{w}}$ cutoff. The major part of the study was on crossflow filtration, but a minor part covered homogenization and extraction, answering the questions regarding whether freezing the biomass affected the homogenization, if longer extraction times allowed more laminarin to be released from 
homogenized seaweed and if the studied homogenization technique leaves seaweed in a state suitable for alginate extraction.

The gained knowledge may increase the utility of $S$. latissima biomass by providing efficient ways to recover its second-most abundant component, laminarin.

\section{Materials and methods}

\section{Materials}

The bulk cultivated Saccharina latissima seaweed was harvested on July 17, 2018, from a cultivation site close to the Sven Lovén Center for Marine Science (University of Gothenburg) on the Swedish west coast. The seaweed was frozen, kept at $-20{ }^{\circ} \mathrm{C}$ and transported to KTH (Royal Institute of Technology in Stockholm) (Scheme 1, step 1). To pool the material, 450-kg frozen seaweed was sawed into smaller pieces, blended thoroughly in a big plastic container, and put in smaller bags of approximately $2.5 \mathrm{~kg}$ each (Scheme 1, step 2). A smaller part of seaweed was harvested fresh close to the Sven Lovén Center on May 2, 2019.

Alginic acid from Macrocystis pyrifera, laminarin from Laminaria digitata, sodium citrate dihydrate ACS reagent $\geq$ $99 \%$, sodium hydroxide $\geq 97 \%$ ACS reagent, and hydrochloric acid 37\% ACS reagent were from Sigma Aldrich. D-(-)Mannitol purum was from KEBO. Deuterium oxide $\left(\mathrm{D}_{2} \mathrm{O}\right)$ (DLM-4-100) 99.9\% was from Cambridge Isotope Laboratories, Inc., and $\mathrm{D}_{2} \mathrm{O}$ (\#87156.0100) $99.96 \%$ was from VWR. Ethanol 99.6\% (v/v) was from VWR.

\section{Processes}

\section{Pre-process}

Approximately $5 \mathrm{~kg}$ of frozen mixed and pooled seaweed was thawed in the plastic bags and mixed in a food processor of the type BOSCH MultiTalent 8 in batches of $300 \mathrm{~g}$ of seaweed at a time, with $1.2 \mathrm{~L}$ added deionized water to each, for $5 \mathrm{~min}$ (Scheme 1, step 3). For every two runs with the food processor, the mixed seaweed was moved to a beaker for further homogenization. The mixed seaweed in the beaker, which had a volume of approximately $3 \mathrm{~L}$, was processed by an Ultra-Turrax (X-1020 Intern. Laborat. App. Dottingen, $\mathrm{GmbH}$ ), with its tip centrally $5 \mathrm{~cm}$ from the bottom in the beaker and run for $10 \mathrm{~min}$ (Scheme 1, step 4). All homogenized seaweed from the Ultra-Turrax treatment was poured into a bigger container, with a volume of $\sim 30 \mathrm{~L}$, in which it was mixed with a propeller blade of $10-\mathrm{cm}$ diameter placed close to the bottom of the container via stirring at $300 \mathrm{rpm}$ for $4 \mathrm{~h}$ (Scheme 1, step 5a). Part of the slurry containing homogenized seaweed was weighed on a Petri dish with a known weight, dried in a desiccator, and weighed again to determine the dry weight of each batch of processed seaweed. Part of the slurry was centrifuged for $5 \mathrm{~min}$ at $3850 \times \mathrm{g}$, and the supernatant was saved for analysis. In the next step, $800 \mathrm{~mL} \mathrm{HCl} \mathrm{(1}$ $\mathrm{M}$ ) was added to the container, and it was stirred for $10 \mathrm{~min}$ more at $300 \mathrm{rpm}$, giving a final $\mathrm{pH}$ of approximately 2.65 (Scheme 1, step 5b). The mixed and acidified algal slurry was poured onto a nylon mesh attached over a box with a length of $45 \mathrm{~cm}$ and a width of $37 \mathrm{~cm}$ in a hanging fashion and left for $1 \mathrm{~h}$ to let the liquid drip through the mesh (Scheme 1, step 6). The nylon mesh was from Derma AB and had $71 \mu \mathrm{m}$ aperture width, $45 \mu \mathrm{m}$ thread diameter, and $37 \%$ open screening area. The filter cake containing seaweed that did not go through the mesh, which typically totaled $8 \mathrm{~kg}$, was saved and used for alginate extraction, and approximately $620 \mathrm{~mL}$ of $\mathrm{NaOH}$ (1 M) was used to neutralize it (Scheme 1, step 7). The permeate that did go through the mesh (typically $18 \mathrm{~kg}$ ) was used for cross-flow filtration, and approximately $180 \mathrm{~mL}$ $\mathrm{NaOH}(1 \mathrm{M})$ was used to neutralize it (Scheme 1, step 8).

\section{Small-scale laminarin and alginate extractions using fresh, frozen, and freeze-dried material}

To test the impact of frozen vs. nonfrozen material, smallscale experiments were performed on algal material that was

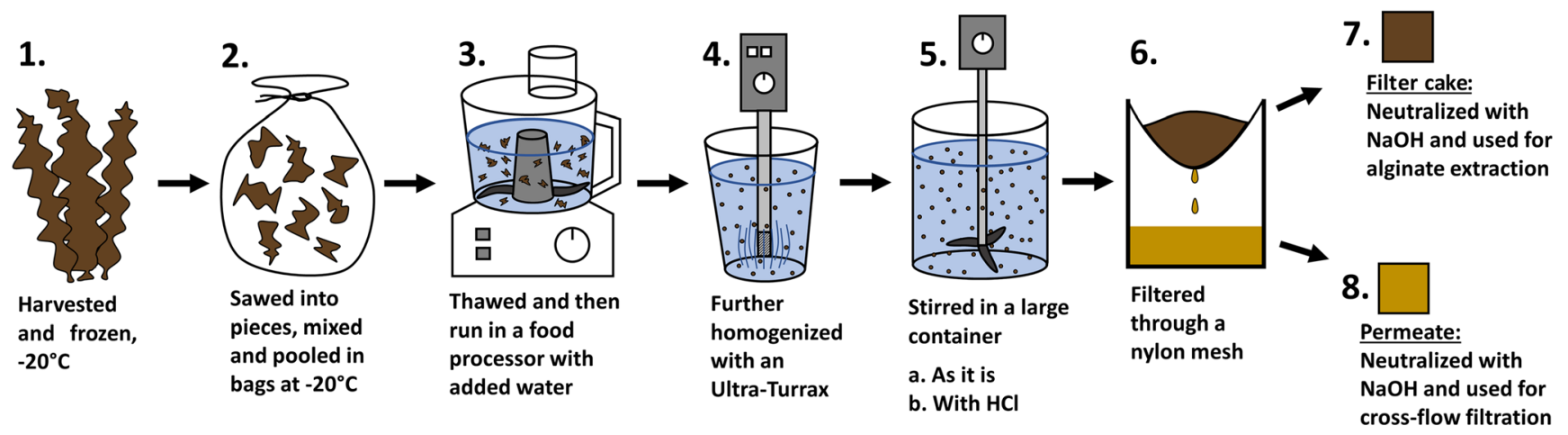

Scheme 1 The process to go from harvested seaweed, through milling, extraction, and filtering to reach a filter cake that can be used for alginate extraction and a permeate that can be used for laminarin extraction 
freshly harvested, cut in pieces with scissors, and mixed, with half of it frozen and the other half processed fresh. These seaweeds were mixed in a food processor for $5 \mathrm{~min}$, just as in the pre-processing, but with $300 \mathrm{~g}$ seaweed to $1.8 \mathrm{~L}$ water. The mixed seaweed was further homogenized with an Ultra Turrax for $10 \mathrm{~min}$, as described in the pre-process (Scheme 1, step 4), but with a volume of $2.1 \mathrm{~L}$, (Scheme 2, step 1). The mixing was followed by homogenization of the seaweed in three replicates both for fresh and frozen seaweed. The homogenized seaweed was then transferred to Falcon tubes, with 2 tubes containing $40 \mathrm{~mL}$ and 2 tubes containing $20 \mathrm{~mL}$ and $20 \mathrm{~mL}$ added sodium citrate $(0.2 \mathrm{M})$. The tubes were put on a shaking board for $16 \mathrm{~h}$ at $150 \mathrm{rpm}$ and a shake radius of $0.5 \mathrm{~cm}$ (Scheme 2, step 2A/B). The sodium citrate was added to dissolve the alginate. The falcon tubes were then centrifuged for $10 \mathrm{~min}$ at $3850 \times \mathrm{g}$ (Scheme 2. step $3 \mathrm{~A} / \mathrm{B})$. The supernatant from the falcon tubes without sodium citrate $(31-35 \mathrm{~mL})$ was transferred to small glass vials, into each of which $3 \mathrm{~mL}$ of sample was transferred and then dried under airflow for less than $6 \mathrm{~h}$ (Scheme 2, step 4A).

The supernatant from the falcon tubes with sodium citrate (31-35 mL) was transferred to other falcon tubes, and then, 10 $\mathrm{mL}$ of $\mathrm{HCl}(1 \mathrm{M})$ was added to precipitate the alginate for $1 \mathrm{~h}$ (Scheme 2, step 4B).

The Falcon tubes with the precipitated alginate were centrifuged for $5 \mathrm{~min}$ at $3850 \times \mathrm{g}$ to form an alginate pellet in the bottom (Scheme 2, step 5B). The liquid above the pellet was discarded, and the pellet was dispersed in deionized water to a total volume of $45 \mathrm{~mL}$ in the tubes, shaken for $30 \mathrm{~min}$, and centrifuged again. The procedure was performed once with water and then four times with an ethanol/water-mix $(60 \% /$ $40 \%(\mathrm{w} / \mathrm{w})$ ) (Scheme 2, step 6B). Afterwards, the alginate pellets were transferred to weighed small plastic Petri dishes, on which it was dried to measure its dry weight (it was dried in the form of acidified alginate, alginic acid) (Scheme 2, step 7B).

An experiment was also made to compare the UltraTurrax-based extraction technique for the extraction of laminarin (Scheme 2, step 1-4A), with that of a harsher protocol when the biomass was powdered and dissolved chemically to remove alginate, and laminarin measured in the solution after alginate removal. This method followed the route of (Scheme 2 , step 1-5B), but with the exception that it started with freezedried powder (of the seaweed used for the main cross-flow filtration study), and that it used sodium carbonate $(0.1 \mathrm{M})$ instead of sodium citrate. The freeze-dried powder was added $0.40 \mathrm{~g}$ to $40 \mathrm{~mL}$ sodium carbonate solution. In this method the supernatant from the first centrifugation of (Scheme 2, step 5B) was not discarded but instead neutralized with hydrochloric acid and dried for the measure of laminarin and mannitol as in (Scheme 2, step 4A).

\section{Cross-flow filtration setup}

The cross-flow filtration is schematically described in Scheme 3. The cross-flow filtration setup had a $60-\mathrm{L}$ tank for the feed solution positioned $30 \mathrm{~cm}$ higher than the pump to give a certain elevation to simplify the filling of an empty pump. Two pumps were used-an internal gear pump from Micropump, Inc., for the lower feed flow speeds and a horizontal multistage centrifugal pump, Grundfos CM-G 3-8, for the higher feed flow speeds. The membrane housing was of the type KERASEP Mini, with a cylindric ceramic membrane sealed in position to make sure that the filter solution only

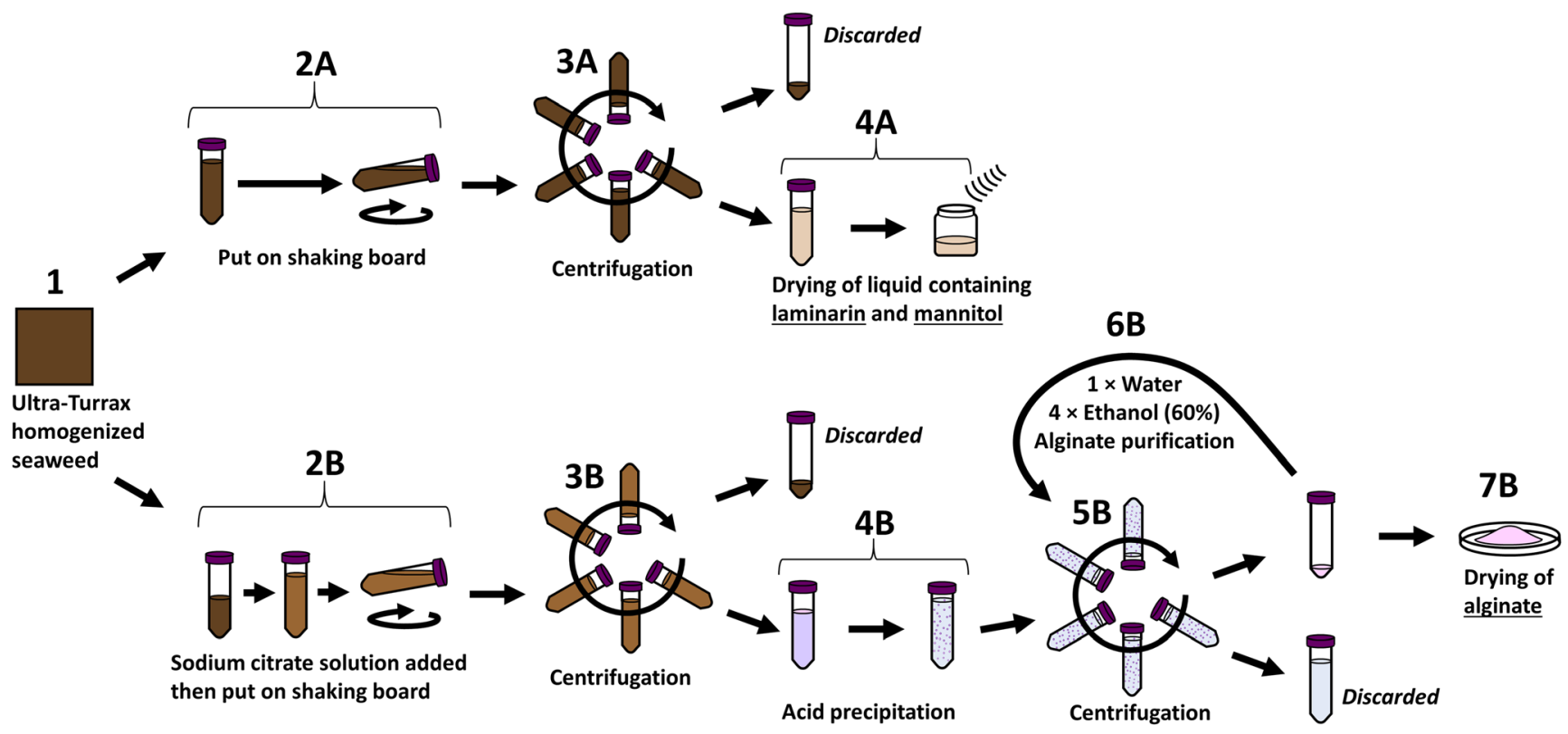

Scheme 2 Small-scale extraction to get samples containing laminarin and mannitol 2A-4A and alginate 2B-7B 


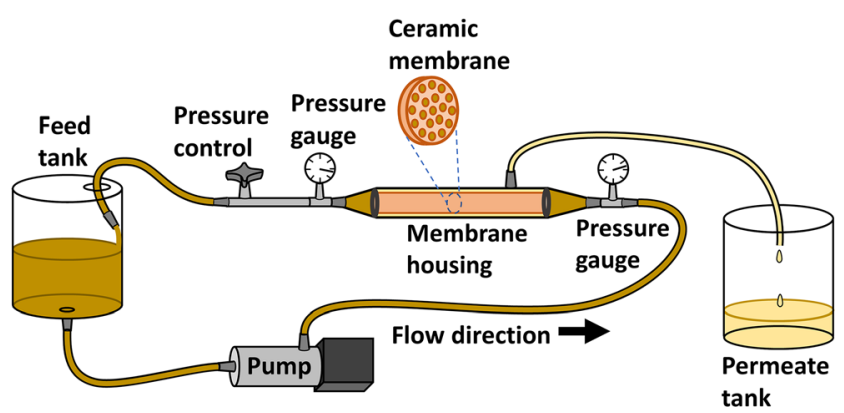

Scheme 3 Cross-flow filtration mode of action

flowed through the axial channels enclosed in the ceramic membrane, while the permeate was pressed out through the filter in the radial direction through the membrane. The volume of the membrane house outside the filter was $0.5545 \mathrm{~L}$. The ceramic membranes $\left(\mathrm{ZrO}_{2} / \mathrm{TiO}_{2}\right.$, monolithic $\mathrm{TiO}_{2}-\mathrm{Al}_{2} \mathrm{O}$ support) were of the brand Kerasep BW from Novasep with stated membrane $\mathrm{M}_{\mathrm{w}}$ cutoffs at $5 \mathrm{kDa}, 15 \mathrm{kDa}$, and $50 \mathrm{kDa}$ (5-, 15-, and 50-kDa membranes). The membranes were $38 \mathrm{~cm}$ long with a diameter of $2.5 \mathrm{~cm}$ and had 19 axial channels each with a diameter of $3.5 \mathrm{~mm}$, giving them an inner area of $0.08 \mathrm{~m}^{2}$. A pressure-control handle was placed after the membrane housing to control the pressure of the feed entering the membrane housing. A pressure gauge was positioned on both sides of the membrane housing to measure the pressure in the feed passing through the channels of the filter. The pressure gauges positioned on each side of the membrane house were also used to record the pressure drop due to friction in the channels of the membrane. All parts of the filtration setup were attached to each other by tubing clamps, bolts with PTFE thread tape, and gaskets with rubber O-rings that were resistant to pressure up to $10 \mathrm{bar}$ and temperatures up to $90^{\circ} \mathrm{C}$. The tubing, which was $5 \mathrm{~m}$ in total, had a diameter of $2.54 \mathrm{~cm}$ and was made of fiber-reinforced synthetic rubber. For some samples, a cooling system was installed with a 30 -m-long 0.8 $\mathrm{cm}$ diameter rubber tube in $0{ }^{\circ} \mathrm{C}$ water, through which the feed was led before it entered the feed tank. In other experiments, the permeate was led directly back to the feed tank, thus keeping the feed volume constant. Between every process, the equipment was thoroughly washed with $\mathrm{NaOH}$ solution of at least $\mathrm{pH} 12.5$ with a temperature of $60^{\circ} \mathrm{C}$ for more than $2 \mathrm{~h}$. This was followed by thorough washing with deionized water.

\section{Cross-flow filtration procedure}

The permeate from the pre-process (Scheme 1, step 8) was loaded into the feed tank and flowed through the cross-flow filtration unit. At several times during the filtration, a sample was gathered from both the feed solution and the permeate solution, with the sample gathered from the tube from which the permeate dripped. At these times, the flow of the permeate per minute was measured, and the total weight of the permeate, the temperature of the feed solution, and the $\mathrm{pH}$ of the feed solution were also recorded. At the end of the filtration, samples were taken from both the feed and the permeate, and a sample was taken from the permeate tank where the permeate from the whole process was mixed. For each sampling, two small glass beakers were filled with $1 \mathrm{~mL}$ and $3 \mathrm{~mL}$ of sample and dried under airflow, drying in under $6 \mathrm{~h}$. The small beakers with dried samples were used for NMR and SEC analyses.

\section{Large-scale alginate extraction}

To demonstrate that the pre-process leaves a filter cake that is useful for alginate extraction, the filter cake was tested as visualized in Scheme 4. The filter cake from the preprocessing of $5-\mathrm{kg}$ frozen algae was used for alginate extraction. The filter cake was neutralized with $\mathrm{NaOH}$, diluted with water to $60 \mathrm{~L}$ with the addition of sodium citrate, and stirred for $16 \mathrm{~h}$ at $300 \mathrm{rpm}$ with a propeller with a diameter of $10 \mathrm{~cm}$ in the solution (Scheme 4, step 1). The solution was diluted to double the volume, totaling $120 \mathrm{~L}$, with water and left for $20 \mathrm{~h}$ to sediment (Scheme 4, step 2). The liquid over the sedimented material was pumped to another container, into which acid was added to reach $\mathrm{pH} 1.6$, which was acidic enough to let the alginate precipitate (Scheme 4, step 3). The liquid with precipitated alginate was poured onto a nylon mesh (the same mesh as in Pre-process), with mechanical scraping by a rotating cylinder with a diameter of $35 \mathrm{~cm}$ rotating at approximately $30 \mathrm{rpm}$ to let the water through but not the acidified alginate (Scheme 4, step 4). After removal, the acidified alginate was dissolved again with the addition of $\mathrm{NaOH}$ to reach a neutral $\mathrm{pH}$ (Scheme 4, step 5). In Scheme 4 , steps $3-5$ were repeated three times and a final step 4 was performed, and after as much water as possible had dripped through the mesh, the acidified alginate was mixed with an equal volume of ethanol, which enabled far more liquid to be squeezed out (by hand). After the final neutralization via Scheme 4, step 5, the neutralized alginate solution was added to plastic trays with a total surface area of $0.7 \mathrm{~m}^{2}$ and left to dry with airflow overnight (Scheme 4, step 6).

\section{Analytical techniques}

\section{${ }^{1} \mathrm{H}-\mathrm{NMR}$}

${ }^{1} \mathrm{H}-\mathrm{NMR}$ was used as the main technique to determine the amounts of laminarin and mannitol in a sample. It was also used to monitor possible bacterial activity during the crossflow filtration process, which was seen as a decrease in mannitol with a simultaneous buildup of acetic, formic, succinic, and lactic acid. NMR samples were prepared by adding $1 \mathrm{~mL}$ of $\mathrm{D}_{2} \mathrm{O}$ to vials with dried material inside, capping the vials and putting them on a shaking board for $5 \mathrm{~h}$, shake frequency of $150 \mathrm{rpm}$, and shake radius of $0.5 \mathrm{~cm}$. To make sure that 


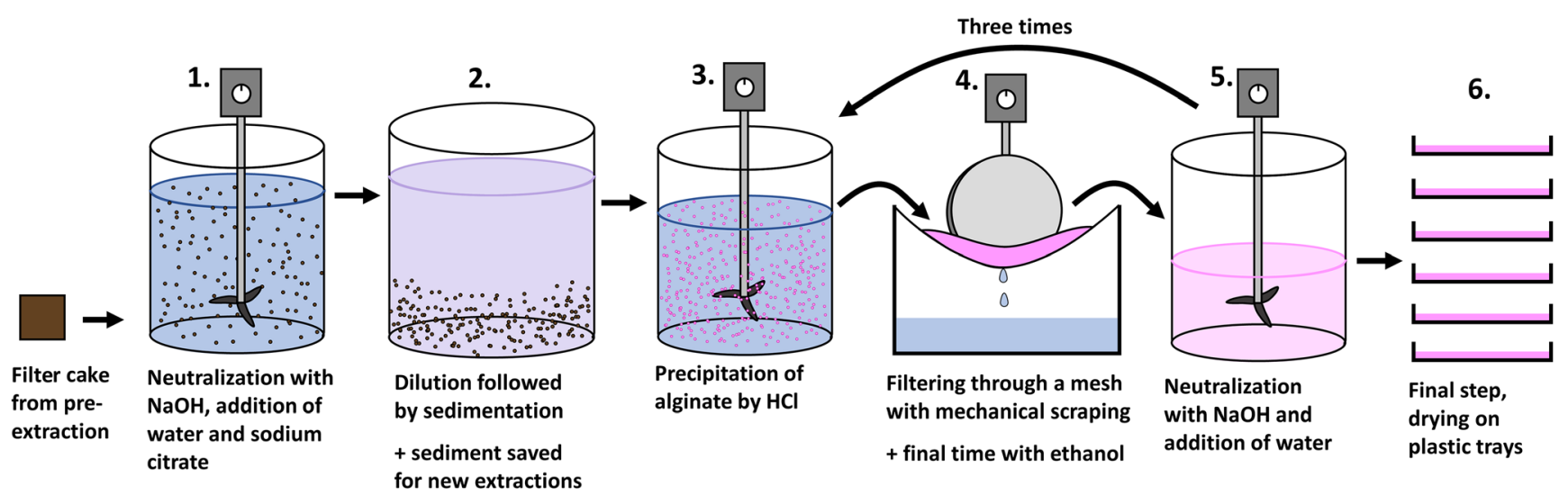

Scheme 4 Alginate extraction from the filter cake after processing

dried material further up on the vial walls also had a chance to dissolve, the vials were manually rotated one by one to let the $\mathrm{D}_{2} \mathrm{O}$ reach the full area of the glass wall, which was a process done three times per samples and initiated after approximately $3 \mathrm{~h}$ of shaking time. In the cases in which particles of solid material were visible after shaking, the vials were centrifuged at $2000 \times g$ for $5 \mathrm{~min}$ to simplify the filling of NMR tubes with mainly liquid contents. The samples were transferred to NMR tubes with $5 \mathrm{~mm}$ diameters. ${ }^{1} \mathrm{H}-\mathrm{NMR}$ spectra were recorded on an Advance 400 (Bruker, USA) spectrometer with the standard ${ }^{1} \mathrm{H}-\mathrm{NMR}$ program and 128 scans for each measurement. MestReNova software was used for data acquisition. To determine the amounts of laminarin and mannitol, peaks were chosen based on the criterion of as little overlap as possible between laminarin and mannitol at the position of the peak. The peak at 3.54 was chosen for laminarin, and the peak at 3.91 was chosen for mannitol. After baseline correction by the

Table 1 Processing results of biomass used for cross-flow and filtration, as well as fresh/frozen biomass. The processes are described in Scheme 1 and Scheme 2. The biomass was diluted with water to 5 times its weight in the homogenization step of the main cross-flow filtration study and 7 times its weight in the prestudy on fresh vs. frozen biomass. \pm is the
Splines-method from MestReNova, the intensity of each peak was recorded. The intensity was normalized by dividing the recorded intensity by the receiver gain value $(\mathrm{RG})$ and the number of scans in each measurement. To correlate the measured normalized intensity with the actual concentration, a calibration curve was made for each compound by making five measurements with different concentrations of the pure compound. For laminarin, the calibration curve was slightly bent since the laminarin peaks became a little thicker with higher concentrations. For mannitol, the curve was straight. The calibration curves for laminarin and mannitol, as well as the spectra, are seen in Table 1.

On one occasion, fractions from SEC (Size exclusion chromatography) were used for NMR analysis. These samples were treated like the other samples with the exception that $0.45 \mathrm{~mL} \mathrm{D} \mathrm{D}_{2} \mathrm{O}$ was used for dissolution and 4100 scans for analysis.

standard deviation, of 23 samples for the frozen biomass of the main cross-flow study, and of 6 samples for the fresh/frozen biomass of the prestudy and the dissolutions with sodium carbonate. The viscosity was measured with at least 3 replicates per temperature

\begin{tabular}{|c|c|c|c|}
\hline & \multirow{2}{*}{$\begin{array}{l}\text { Processing before cross-flow } \\
\text { filtration (Scheme 1) } \\
\text { Frozen biomass }\end{array}$} & \multicolumn{2}{|c|}{ Prestudy: fresh vs. frozen biomass (Scheme 2) } \\
\hline & & Frozen biomass & Fresh biomass \\
\hline Dry weight of biomass average $(\% \mathrm{w} / \mathrm{w})$ & $11.00 \pm 1.02$ & $5.70 \pm 0.15$ & $4.88 \pm 0.18$ \\
\hline Laminarin solubilized from non-dried biomass (\% w/w) & $2.70 \pm 0.467$ & $0.965 \pm 0.149$ & $0.083 \pm 0.046$ \\
\hline Alginate extracted from non-dried biomass $(\% \mathrm{w} / \mathrm{w})$ & 4.60 & $2.39 \pm 0.19$ & $2.42 \pm 0.07$ \\
\hline Permeate through the nylon mesh average ratio $(\% \mathrm{w} / \mathrm{w})$ & $70.2 \pm 6.3$ & $\mathrm{x}$ & $\mathrm{x}$ \\
\hline \multicolumn{4}{|c|}{ Other tests on the biomass used for the cross-flow filtration study } \\
\hline \multicolumn{2}{|c|}{ Laminarin solubilized from biomass at $25^{\circ} \mathrm{C}$ for $0,1,4,20 \mathrm{~h}$ and at $65^{\circ} \mathrm{C}$ for $20 \mathrm{~h}(\% \mathrm{w} / \mathrm{w})$} & \multicolumn{2}{|c|}{$\begin{array}{l}25^{\circ} \mathrm{C}: 2.96,2.91,3.03,3.02 \\
65^{\circ} \mathrm{C}: 2.95\end{array}$} \\
\hline \multicolumn{2}{|c|}{$\begin{array}{l}\text { Laminarin solubilized from freeze-dried pulverized biomass with sodium carbonate } \\
\text { (\% w/w, of the frozen biomass) }\end{array}$} & \multicolumn{2}{|c|}{ Laminarin: $2.699 \pm 0.055$} \\
\hline \multicolumn{2}{|c|}{$\begin{array}{l}\text { Dynamic viscosity of feed solution determined by capillary viscometry at } 14,20,25 \\
\text { and } 37^{\circ} \mathrm{C}\left(\mathrm{mm}^{2} \mathrm{~s}^{-1}\right)\end{array}$} & \multicolumn{2}{|c|}{$\begin{array}{l}14^{\circ} \mathrm{C}: 1.395 \pm 0.020 \\
20^{\circ} \mathrm{C}: 1.201 \pm 0.008 \\
25^{\circ} \mathrm{C}: 1.072 \pm 0.001 \\
37^{\circ} \mathrm{C}: 0.851 \pm 0.001\end{array}$} \\
\hline \multicolumn{2}{|c|}{$\begin{array}{l}\text { Particles in feed solution determined by centrifugation, } 3850 \times g \text {, and by comparing the } \\
\text { dry weight of pellet and supernatant }(\% \mathrm{w} / \mathrm{w})\end{array}$} & \multicolumn{2}{|l|}{0.122} \\
\hline
\end{tabular}




\section{Size exclusion chromatography}

SEC was used to determine the $M_{w}$ and eventual change in the $\mathrm{M}_{\mathrm{w}}$ of laminarin during processing by cross-flow filtration. SEC samples were prepared by letting $1 \mathrm{~mL}$ of a sample dry in a small vial, as assisted by airflow. For every new filtration, a sample was also prepared for the solution right before the start of filtration, and one sample was taken before the acid addition and filtration in Scheme 1, steps 5b-6. The samples taken before filtration were centrifuged for $5 \mathrm{~min}$ at $3850 \times \mathrm{g}$ to remove debris, and then, the supernatant was dried in a vial, as were the other samples. To the vials containing dry material, 5 $\mathrm{mL}$ of deionized water was added, and the vials were put on a shaking board for $4 \mathrm{~h}$. The estimation of the $\mathrm{M}_{\mathrm{w}}$ distribution of the samples was conducted using a Dionex Ultimate-3000 HPLC system (Dionex, USA). The sample concentration was $1 \mathrm{~g} \mathrm{~L}^{-1}$, and each sample was filtered through a $0.2-\mu \mathrm{m}$ Nylon filter. Sodium hydroxide $(0.010 \mathrm{M})$ was used as the eluent, the elution rate was $1 \mathrm{~mL} \mathrm{~min}{ }^{-1}$, and the temperature in the system was kept at $40^{\circ} \mathrm{C}$. Three PSS Suprema columns (Polymer Standard Services, Germany) were connected in series, all with the dimensions of $300 \times 8 \mathrm{~mm}$ and particle size of $10 \mu \mathrm{m}$, and pore sizes of $3.0 \mathrm{~nm}$ and $2 \times 100 \mathrm{~nm}$. A refractive index detector by Waters (Waters-410, USA) was used for detection. The $\mathrm{M}_{\mathrm{w}}$ standards were a series of pullulan polymers in the range $\mathrm{M}_{\mathrm{w}}: 0.342$ to $805 \mathrm{kDa}\left(\mathrm{M}_{\mathrm{n}}: 0.342-708\right.$ $\mathrm{kDa}$ ). Chromeleon 7.1 was used as the data processing software. For clarity, $\mathrm{M}_{\mathrm{w}}$ refers to the weighted average of molecular weight distribution and $\mathrm{M}_{\mathrm{n}}$ the number average.

On one occasion, the eluent from the SEC was gathered in fractions from 9 consecutive runs of the same sample. The fraction where gathered in the intervals between the time points 11:30, 16:30, 21:00, 23:24, 25:12, 27:00, and 29:30 (min:s), corresponding to $\mathrm{M}_{\mathrm{w}}$ points of "124000," 1120, 31.9, 6.46, 2.26, 0.905, and $0.320 \mathrm{kDa}$. All fractions of each interval were pooled, neutralized with $\mathrm{HCl}$, and dried under high airflow divided into five $10-\mathrm{mL}$ glass vials until the liquid could be transferred in one of the vials where the drying continued until completion, and the fraction sample was used as a sample for NMR $\left({ }^{1} \mathrm{H}-\mathrm{NMR}\right)$.

\section{Viscosity measurement}

The kinematic viscosity was measured with a capillary tube viscometer (Xylem Analytics Germany $\mathrm{GmbH}$, prod. nr: 501 10/I, k-factor $0.009701 \mathrm{~mm}^{2} \mathrm{~s}^{-2}$ ) placed in a tank of $100 \mathrm{~L}$ water with temperature controlled to a precision of $0.1{ }^{\circ} \mathrm{C}$. Prior to measurement, the solution was centrifuged for $5 \mathrm{~min}$ at $3850 \times \mathrm{g}$ and only the part of the particle-free supernatant was used for viscosity measurement.

\section{Results}

\section{Pre-processing results and results from the study on fresh vs. frozen biomass}

Saccharina latissima can serve as a source of both laminarin and alginate. We previously showed that a solution of sodium citrate works well for the extraction of alginate due to the strong chelation of the citric acid anion, which also occurs at a neutral pH (Sterner and Edlund 2016). A common technique used to extract more alginate with a more dilute extraction solution is to first apply an acid pretreatment step on the algae. In this paper, we focus on the extraction of laminarin from the acidic solution that is left after acid pretreatment of seaweed, with the help of cross-flow filtration. Most of the experiments were performed on frozen biomass, but since freezing can make a difference in extractions, a test was performed to determine to what extent alginate and laminarin can be extracted from fresh and frozen biomass. The results from the processing of the biomass that was later used for cross-flow filtration, as well as the comparison between the processing of fresh and frozen seaweed biomass, are presented in Table 1.

The extraction of laminarin was done with the same homogenization equipment and similar concentrations, extraction times, and amounts of stirring in all cases. The amounts of extracted compounds varied greatly between the two different batches of frozen biomass. The batch of biomass used mainly for this study had a higher laminarin content compared to the biomass used for the comparison of fresh and frozen biomass. More laminarin was extracted from the frozen biomass than from the fresh biomass. When the time and temperature of stirring the solution was set between $0-20 \mathrm{~h}$ and $25^{\circ} \mathrm{C}$ and $65^{\circ} \mathrm{C}$ it was seen that the amount of laminarin extracted did not vary greatly with these setting. It was seen that the amount of laminarin extracted did not vary greatly with these settings. Also, when laminarin was solubilized by dissolving freeze-dried and pulverized biomass in sodium carbonate and measuring laminarin in the solution, after the removal of alginate by acid precipitation, the amount of extracted laminarin was similar to the ordinary method of solubilizing laminarin. Alginate was extracted from frozen and fresh biomass with little difference, especially when accounting for the higher dry weight of the frozen biomass.

\section{Cross-flow filtration study}

The goal of the study was to determine which settings are suitable for cross-flow filtration for the extraction of laminarin. To evaluate this, a number of batches with processed homogenized biomass were produced and used for the study. In Table 2, there is a summary of which process parameters were evaluated.

The lower liquid velocity generates less heat, which simplifies the cooling of the system. For several of the 
Table 2 Schematic table of parameters that were tested for the filtrations

\begin{tabular}{llllllll}
\hline Pump & Pump speed & Feed velocity & Temperature & Membrane & Pressure & Volume & Mode \\
\hline Gear pump & $2 \mathrm{~L} \mathrm{~min}^{-1}$ & $0.2 \mathrm{~m} \mathrm{~s}^{-1}$ & $10-13{ }^{\circ} \mathrm{C}$ & $5,15,50 \mathrm{kDa}$ & $5 \mathrm{bar}$ & $17-21 \mathrm{~L}$ & Filtration \\
Gear pump & $16 \mathrm{~L} \mathrm{~min}^{-1}$ & $1.7 \mathrm{~m} \mathrm{~s}^{-1}$ & $\begin{array}{l}34-36^{\circ} \mathrm{C} \\
40\end{array}$ & $50 \mathrm{kDa}$ & $2 \mathrm{bar}$ & $15-17 \mathrm{~L}$ & Filtration \\
Centrifugal pump & $52 \mathrm{~L} \mathrm{~min}^{-1}$ & $4.7 \mathrm{~m} \mathrm{~s}^{-1}$ & Ramp up to $50-68^{\circ} \mathrm{C}$ & $5,15,50 \mathrm{kDa}$ & $2,3,5 \mathrm{bar}$ & $\begin{array}{l}\text { Standard: } 15-17 \mathrm{~L} \\
\text { Once: } 65,55 \mathrm{~L}\end{array}$ \\
\hline
\end{tabular}

experiments with $0.2 \mathrm{~m} \mathrm{~s}^{-1}$ feed velocity, we applied cooling by circulating the liquid through an ice bath, as a way of delaying the biological attack of the feed. A higher pump speed with a high feed velocity, which is the signum for cross-flow filtration, reduces the amount of membrane fouling that occurs on the ceramic membrane. In later experiments, a higher feed velocity and higher temperature were used since it was shown to be more effective; in these experiments, no cooling was used. The ceramic membranes separate molecules based on their $\mathrm{M}_{\mathrm{w}}$, which is related to their hydrodynamic volume. Three different membranes were evaluated, 5 , 15 , and $50 \mathrm{kDa}$, in order to find membranes with two functions - a membrane with a high passage ratio of laminarin but that filter of particles and larger molecules such as proteins (prefiltering) and the other membrane with low laminarin passage ratio to make sure laminarin becomes concentrated in the feed. Except at times when the temperature increased rapidly, the flux through the membrane decreased gradually because of membrane fouling. To study the longtime effects of filtration settings, some experiments were done with reflux of the permeate directly back to the feed to achieve a steady state.

The pressure is written as 2,3 , or 5 bar as the pressure before the filter (feed pressure), while for the higher feed velocity $\left(4.7 \mathrm{~m} \mathrm{~s}^{-1}\right)$, there was a pressure drop caused by the resistance in the ceramic membrane filter channels, so the feed pressure before the filter was 0.5 bar higher than the pressure after. In the cases of a lower feed velocity, the pressure drop was considered neglectable. The average pressure over the membrane (transmembrane pressure) was calculated as:

transmembrane pressure $=$

(permeate pressure-pressure drop )/2(1)

\section{Filtrations with a lower feed velocity and cooling}

At a lower feed velocity, the permeate flux was low, causing the filtration to take a long time. During the course of the filtration, the laminarin passage ratio was gradually reduced, measured by $1 \mathrm{H}-\mathrm{NMR}$ in the feed and permeate solution (Figs. 1 and 2a-d). The logarithmic scale of laminarin concentration was chosen since, at a steady passage ratio, the feed and permeate lines keep a constant distance between them.
The laminarin passage ratio was $37 \%$ for the $50-\mathrm{kDa}$ membrane (Fig. 2a). Even less, 30\% went through the $15-\mathrm{kDa}$ membrane, and $14 \%$ went through the $5-\mathrm{kDa}$ membrane. The average laminarin passage ratio through the 5-kDa membrane increased somewhat to $17 \%$ when the temperature was increased to $36^{\circ} \mathrm{C}$. The probable cause of the low amount of laminarin that passed through the filter is that the thick gel layer and membrane fouling effectively reduced the pore size of the membrane so that it did not separate molecules of the size for which it is designed. The membrane fouling increased during the course of the filtration, and it was seen as a constant decrease of the laminarin passage ratio. Since data on passage ratio was gathered at different times and with different amounts of remaining feed for each filtration experiment, a question arose concerning how to best report the average laminarin passage ratio. Two ways to report were tested for this - the passage ratio was measured as a linear trend of either the remaining feed volume or the filtration time. Then, the linear trends were used to report the passage ratio at half of the filtration time or at half of the filtrated volume. These two measures gave fairly similar results, and these results were also similar to that from taking the plain average of the laminarin passage ratio.

The membrane permeates flux decreased rapidly during the course of the filtration, as shown by the individual permeate flux curves in Fig. 2a-d and shown as the difference from the starting flux to the average flux for the first half of filtration (100-50\% remaining feed), which was a reduction by more than a third of the value. For the third quarter of the filtration (50-25\% remaining feed), the flux was reduced yet again by more than one-third of the value.

\section{Filtrations with a higher feed velocity}

With a higher feed velocity over the membrane, the flux increases greatly. The laminarin passage ratio was high when high feed velocities were used together with a 50-kDa membrane. The medium-high feed velocity of $1.5 \mathrm{~m} \mathrm{~s}^{-1}$ gave an $\sim 57 \%$ laminarin passage ratio, and with a $4.7 \mathrm{~m} \mathrm{~s}^{-1}$ feed velocity, a passage ratio of $75 \%$ was achieved, in contrast to the passage ratio of $\sim 37 \%$ with the low feed velocity of $0.2 \mathrm{~m} \mathrm{~s}^{-1}$ (Fig. 3e-f). The flux was also heavily increased with an increased feed velocity. The flux increases at the beginning of the filtrations are due to the increases in temperature. The highest temperature stated in the 
Fig. $1{ }^{1} \mathrm{H}-\mathrm{NMR}$ spectra for a sample, laminarin and mannitol, as well as calibration curves for laminarin and mannitol

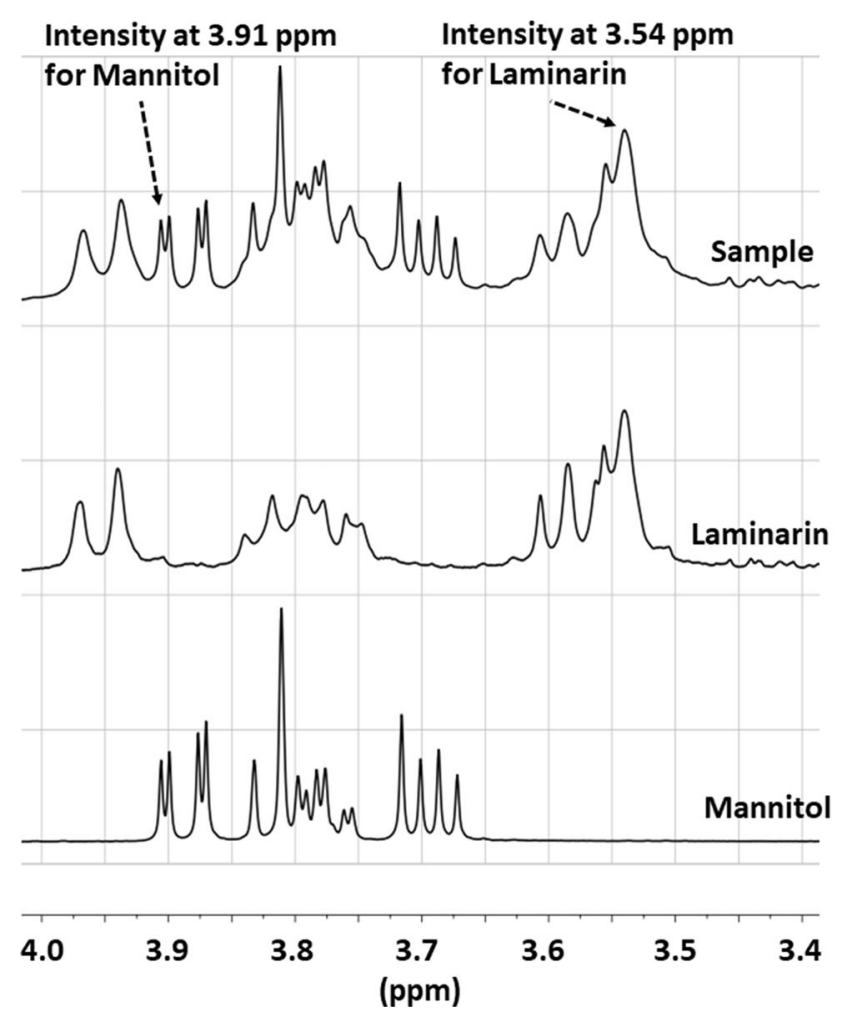

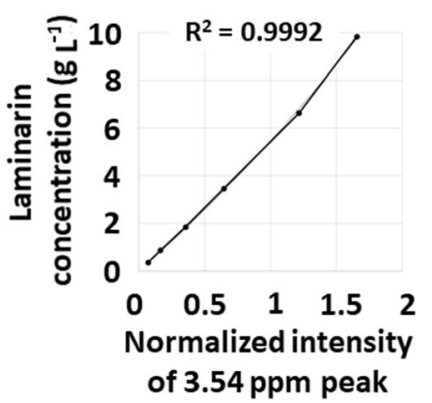

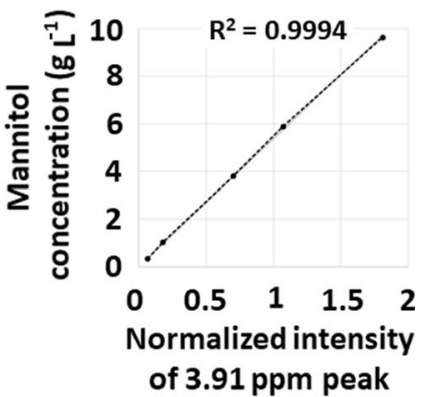

upper right of Fig. 3e-h was achieved in close connection with the point of the highest flux. The small drop in flux that occurred at the beginning of the filtration with a $50-\mathrm{kDa}$ membrane was most likely due to initial filter membrane fouling that was soon
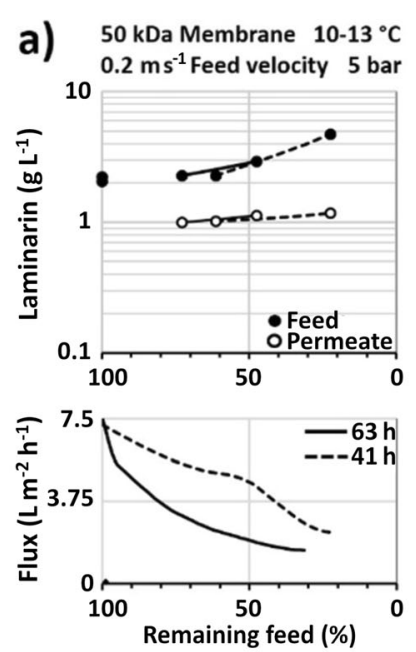
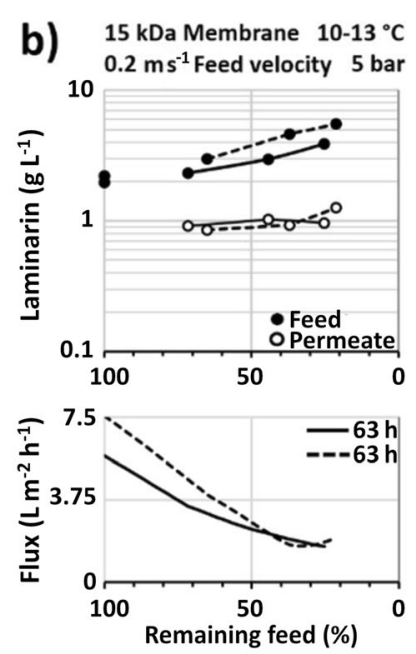
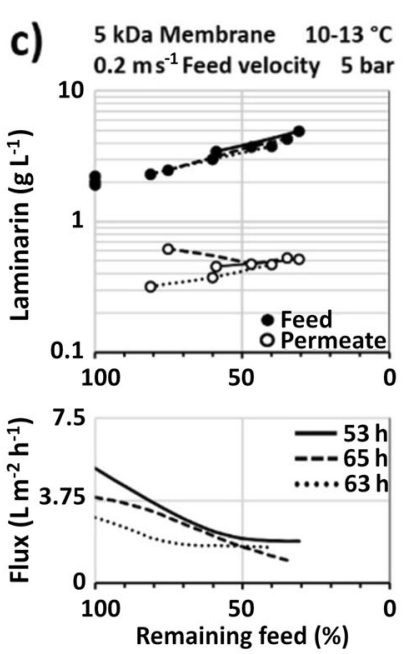
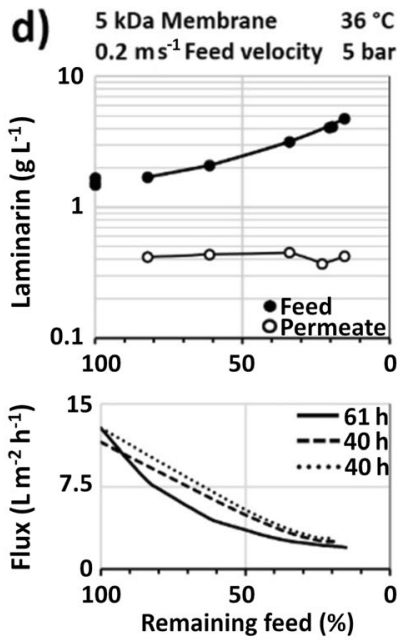

\begin{tabular}{|l|c|c|c|c|}
\hline \multirow{2}{*}{} & \multicolumn{4}{|c|}{ Laminarin passage ratio (\%): Permeate/feed } \\
\cline { 2 - 5 } & a) & b) & c) & d) \\
\hline Average \pm std & $37.4 \pm 7.5$ & $29.7 \pm 6.9$ & $14.0 \pm 4.5$ & $17.1 \pm 7.0$ \\
\hline Average by half vol. & 37.7 & 30.0 & 13.4 & 17.5 \\
\hline Average by half time & 37.5 & 30.0 & 15.2 & 16.9 \\
\hline
\end{tabular}

\begin{tabular}{|l|c|c|c|c|}
\hline \multirow{2}{*}{} & \multicolumn{4}{|c|}{ Permeate Flux $\left(\mathbf{L m}^{-2} \mathbf{~}^{-\mathbf{1}}\right)$} \\
\cline { 2 - 5 } & a) & b) & c) & d) \\
\hline Average at initiation & 6.7 & 5.8 & 4.0 & 11.9 \\
\hline Average $\mathbf{1 0 0}-\mathbf{5 0} \%$ rem. feed & 3.7 & 3.2 & 2.5 & 7.3 \\
\hline Average $\mathbf{5 0}-\mathbf{2 5} \%$ rem. feed. & 2.1 & 1.8 & & 3.4 \\
\hline
\end{tabular}

Fig. 2 Filtrations with a lower feed velocity with and without cooling. Plots: Laminar concentration and permeate flux versus the remaining feed ratio (current feed vol./starting feed vol.). The membrane $\mathrm{M}_{\mathrm{w}}$ cutoff, steady-state temperature, feed velocity, and feed pressure are specified over each plot. The altered settings in $\mathbf{a}-\mathbf{d}$ are the membrane $\mathrm{M}_{\mathrm{w}}$ cutoff and the temperature. Straight, striped, and dotted lines indicate duplicate filtrations with the same settings. The time from the start to the end of each filtration is indicated as an inset in the permeate flux plots. Tables: Average values for the laminarin passage ratio and permeate flux for filtrations a-d. \pm is the standard deviation for all measured laminarin passage ratios (n) at each filtration setting, $n=4,6,8,5$ for $\mathbf{a}, \mathbf{b}, \mathbf{c}, \mathbf{d}$ 

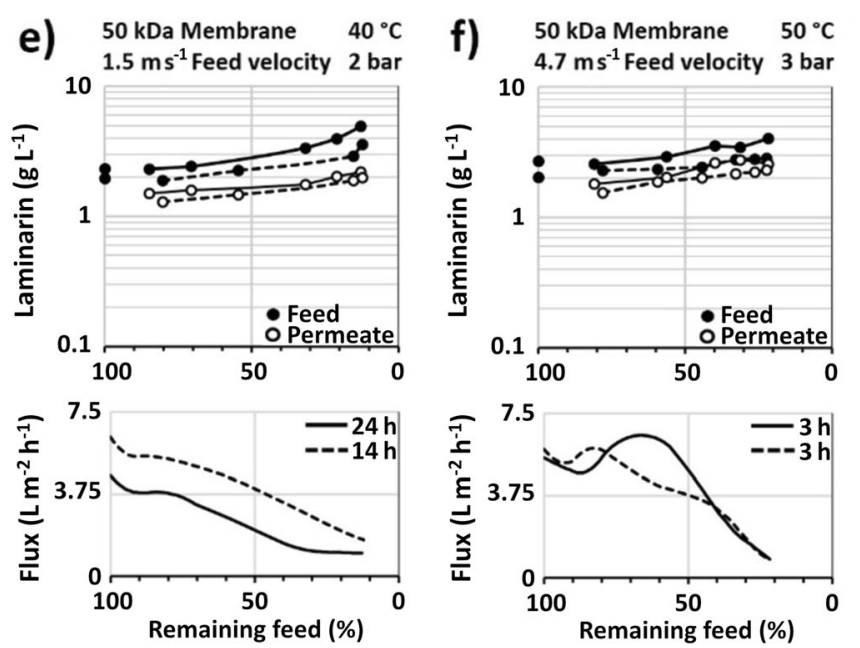

\begin{tabular}{|l|c|c|c|c|}
\hline \multirow{2}{*}{} & \multicolumn{4}{|c|}{ Laminarin passage ratio (\%): Permeate/feed } \\
\cline { 2 - 5 } & e) & f) & g) & h) \\
\hline Average \pm std & $57.3 \pm 8.5$ & $75.0 \pm 6.4$ & $42.2 \pm 11.0$ & $16.8 \pm 2.2$ \\
\hline Average by half vol. & 57.3 & 74.4 & 42.3 & 16.2 \\
\hline Average by half time & 58.0 & 74.7 & 38.6 & 17.8 \\
\hline
\end{tabular}

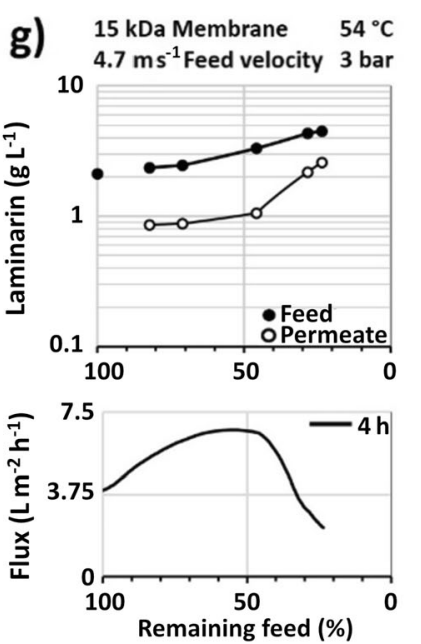

h) $\begin{array}{ll}5 \mathrm{kDa} \text { Membrane } & 60^{\circ} \mathrm{C} \\ 4.7 \mathrm{~m} \mathrm{~s}^{-1} \text { Feed velocity } & 3 \mathrm{bar}\end{array}$
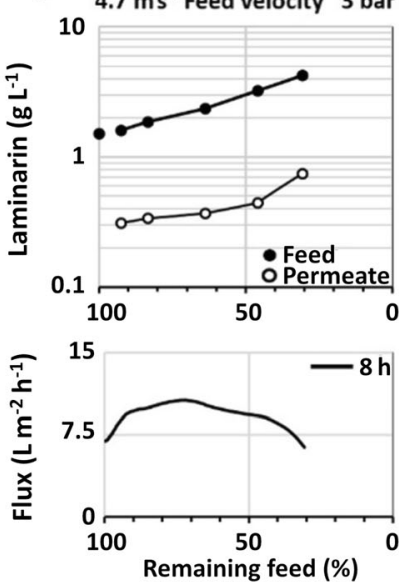

Fig. 3 Filtrations with higher feed velocity. Plots: Laminar concentration and permeate flux plotted versus the remaining feed ratio (current feed vol./starting feed vol.). The membrane $\mathrm{M}_{\mathrm{w}}$ cutoff, max temperature, feed velocity, and feed pressure are specified over each plot. The altered settings in $\mathbf{e}-\mathbf{f}$ are the feed velocity and feed pressure. The altered setting in $\mathbf{f}-\mathbf{h}$ is the membrane $M_{w}$ cutoff. Straight, striped, and dotted lines indicate duplicate filtrations with the same settings. The time from

\begin{tabular}{|l|c|c|c|c|}
\hline \multirow{2}{*}{} & \multicolumn{4}{|c|}{ Permeate Flux $\left(\mathbf{L ~ m}^{-2} \mathbf{h}^{-1}\right)$} \\
\cline { 2 - 5 } & e) & f) & g) & h) \\
\hline Average at initiation & 21.9 & 90.7 & 31.5 & $13-9$ \\
\hline Average maximum & 21.9 & 99.4 & 53.6 & 21.3 \\
\hline Average $\mathbf{1 0 0}-\mathbf{5 0 \%}$ rem. feed & 16.1 & 83.6 & 45.1 & 19.3 \\
\hline Average $\mathbf{5 0}$ - 25\% rem. feed. & 8.1 & 37.7 & 34.7 & 16.8 \\
\hline
\end{tabular}

the start to the end of each filtration is indicated as an inset in the permeate flux plots. Tables: Average values for the laminarin passage ratio and permeate flux for filtrations $\mathbf{e}-\mathbf{h}$ (when only one filtration was done at a specific setting, the average is just the value for that filtration). \pm is the standard deviation for all measured laminarin passage ratios $(n)$ at each filtration setting, $n=9,11,5,5$ for $\mathbf{e}, \mathbf{f}, \mathbf{g}, \mathbf{h}$

tube. The experiment without reflux that could compare in terms of time was a big filtration of 65 L solution (Fig. 4 l). From the start of the filtration, the laminarin passage ratio decreased steadily with time, and it decreased faster with increased feed pressure, as seen in Fig. 4i-j. An immediate difference between the feed pressure at 5 bar and 2 and, 3 bar was seen, but after a longer time, a difference was also seen between 2 bar and 3 bar. The difference between 3 and 2 bar was observed after $3 \mathrm{~h}$ and was definitely observed after $6 \mathrm{~h}$ and at $24 \mathrm{~h}$. The observed decrease in the laminarin passage ratio was most likely caused by membrane fouling. After $48 \mathrm{~h}$, biological activity in the 2-bar filtration had attacked the laminarin in the system (see below). More on biological activity is found later in Fig. 6 and Table 3. The filtrations at 3 and 5 bar showed a distinct maximum flux peak before decreasing again due to membrane fouling, which was not seen for the filtration at 2 bar. An increase in the temperature increased the permeate flux, as seen in Fig. 4i-l (lower right plot). More information on flux changes with temperature is found in Table 4 .

\section{The effect of pressure on 5-kDa filtrations (with reflux circulation or a high initial volume)}

The experiments with reflux were performed for $48 \mathrm{~h}+$, during which time the permeate was led back into the feed by a thin 
Table 3 Starting concentration of mannitol, the degradation of mannitol per hour as a percentage of the starting concentration, and the average exponential curve that describe the mannitol ratio per time $t$ in hours (mannitol ratio being mannitol divided by starting mannitol). The curve is calculated as the average of the individual log-linear regressions for each filtration (a linear curve fit with $\ln (\mathrm{m})$ as $\mathrm{y}$-axis and $t$ as the $\mathrm{x}$-axis). The degradation of mannitol per hour is equal to the exponent of the mannitol ratio expression. \pm is the standard deviation

\begin{tabular}{llll}
\hline & Filtrations & Mannitol concentration $\left(\mathrm{g} \mathrm{L}^{-1}\right)$ \\
\hline Homogenized solutions before filtrations & 25 & $1.96 \pm 0.36$ & Mannitol ratio $t(\mathrm{~h})$ \\
& Filtrations & Mannitol degradation $\left(\% \mathrm{~h}^{-1}\right)$ & $\mathrm{e}^{-0.0225 \cdot \mathrm{t}}\left(R^{2} 0.62^{*}\right)$ \\
Degradation with cooling, $10-13{ }^{\circ} \mathrm{C}$ & 12 & $2.25 \pm 1.44$ & $\mathrm{e}^{-0.0864 \cdot \mathrm{t}}\left(R^{2} 0.88^{*}\right)$ \\
Degradation without cooling, $37-66^{\circ} \mathrm{C}$ & 10 & $8.64 \pm 3.43$ & $-0.16 \pm 1.50$ \\
Degradation after prefiltering, $57-61^{\circ} \mathrm{C}$ & 3 & $\mathrm{e}^{0.0016 \cdot \mathrm{t}}\left(R^{2} 0.91^{*}\right)$ \\
\hline
\end{tabular}

*Average $R^{2}$ for the fitted curve of each individual filtration in the category

tube. The experiment without reflux that could compare in terms of time was a big filtration of $55 \mathrm{~L}$ solution (Fig. 5p). In the reflux filtrations with 5-kDa membranes, the laminarin passage ratio decreased steadily with time and decreased faster with a higher feed pressure. The filtration at 2 bar with a $5-\mathrm{kDa}$ membrane (Fig. 5 o) showed signs of a biological attack on laminarin after $48 \mathrm{~h}$. More on biological activity is found later. An increase in temperature increased the flux, especially for filtration (p) that had been prefiltered (Fig. $5 \mathrm{~m}-\mathrm{p}$, lower right plot). In Table 4, the relation between the temperature and the increase in flux is described further.

\section{Filtrations with previously filtered samples and signs of biological activity}

For comparable filtrations only differing in terms of the filter membrane used, it is seen that a higher $\mathrm{M}_{\mathrm{w}}$ cutoff gave a higher permeate flux (Fig. 6q). Initially, the change from a $5-\mathrm{kDa}$ to a $15-\mathrm{kDa}$ membrane roughly doubled the permeate flux, and the change from 15 to $50 \mathrm{kDa}$ roughly doubled it again. Prefiltering the solutions through a 50-kDa membrane showed the potential to increase the permeate flux for filtrations with 5-kDa membranes (Fig. 5p). When comparative reflux filtrations were performed with 5-kDa membranes with ordinary feeds and feeds that had been prefiltered through either $15-\mathrm{kDa}$ or $50-\mathrm{kDa}$ membranes, it revealed a permeate flux increase for the two prefiltering cases but also showed that the laminarin passage ratio increased drastically in the $15 \mathrm{kDa}$ prefiltering case but not in the other cases (Fig. 6r). During the course of the extractions, on a few occasions, the laminarin content decreased, as seen in Fig. $6 \mathrm{~s}-\mathrm{t}$. This is attributed to biological activity. Several indications of this effect were observed, such as a smell, a decreased $\mathrm{pH}$, and the formation of organic acids, including acetic, formic, lactic,

Table 4 Permeate flux minimum, maximum and "steady state" (24-h value) for the different pressures and temperatures and the flux normalized to 1 bar pressure and the viscosity at $20^{\circ} \mathrm{C}$ temperature. In the lower

part, flux is shown as a function of temperature and viscosity for the linear stage when the temperature increase occurs faster than membrane fouling

\begin{tabular}{|c|c|c|c|c|c|c|c|c|c|}
\hline \multirow[b]{3}{*}{ Flux initial $\min \left(\mathrm{L} \mathrm{m}^{-2} \mathrm{~h}^{-1}\right)$ at the temperature $\left({ }^{\circ} \mathrm{C}\right)$} & \multicolumn{3}{|c|}{$5 \operatorname{bar}\left(4.75^{\mathrm{a}}\right)$} & \multicolumn{4}{|c|}{$3 \operatorname{bar}\left(2.75^{\mathrm{a}}\right)$} & \multicolumn{2}{|c|}{$2 \operatorname{bar}\left(1.75^{\mathrm{a}}\right)$} \\
\hline & \multirow{2}{*}{$\begin{array}{l}5 \mathrm{kDa} \\
28.7 \quad 30\end{array}$} & $5 \mathrm{kDa}^{\mathrm{b}}$ & $50 \mathrm{kDa}$ & $5 \mathrm{kDa}$ & $5 \mathrm{kDa}^{\mathrm{b}}$ & $15 \mathrm{kDa}$ & $50 \mathrm{kDa}$ & $5 \mathrm{kDa}$ & $50 \mathrm{kDa}$ \\
\hline & & $29.9 \quad 26$ & $78.9 \quad 38$ & $10.8 \quad 22$ & 14.626 & $39.8 \quad 20$ & $85.5 \quad 36$ & $12.1 \quad 32$ & $54.2 \quad 22$ \\
\hline Flux at $\max \left(\mathrm{L} \mathrm{m}^{-2} \mathrm{~h}^{-1}\right)$ at the temperature $\left({ }^{\circ} \mathrm{C}\right)$ & 34.151 & $44.2 \quad 54$ & $111.2 \quad 61$ & $20.9 \quad 55$ & 26.960 & $64.5 \quad 55$ & $111.8 \quad 56$ & $15.0 \quad 51$ & $80.5 \quad 52$ \\
\hline Flux 24-h value $\left(\mathrm{L} \mathrm{m}^{-2} \mathrm{~h}^{-1}\right)$ at the temperature $\left({ }^{\circ} \mathrm{C}\right)$ & $27.5 \quad 65$ & & 101.164 & $13.0 \quad 60$ & 18.560 & $60.0 \quad 59$ & $78.0 \quad 59$ & 13.258 & $61.5 \quad 58$ \\
\hline Flux initial $\min \left(\mathrm{L} \mathrm{m}^{-2} \mathrm{~h}^{-1}\right)$ normalized to $1 \mathrm{bar}, 20^{\circ} \mathrm{C}$ & 4.8 & 5.5 & 11.3 & 3.7 & 4.6 & 14.5 & 21.9 & 5.3 & 29.6 \\
\hline Flux at $\max \left(\mathrm{L} \mathrm{m}^{-2} \mathrm{~h}^{-1}\right)$ normalized to $1 \mathrm{bar}, 20^{\circ} \mathrm{C}$ & 3.9 & 4.8 & 10.8 & 3.8 & 4.5 & 11.8 & 20.2 & 4.6 & 24.3 \\
\hline Flux 24-h value $\left(\mathrm{L} \mathrm{m}^{-2} \mathrm{~h}^{-1}\right)$ normalized to $1 \mathrm{bar}, 20^{\circ} \mathrm{C}$ & 2.5 & & 9.4 & 2.2 & 3.1 & 10.3 & 13.4 & 3.6 & 16.9 \\
\hline \multicolumn{10}{|c|}{ For the linear region, when temperature rise goes faster than membrane fouling } \\
\hline Flux change $(\%)$ per ${ }^{\circ} \mathrm{C}$ & 0.84 & 1.43 & 1.41 & $\begin{array}{l}1.45 \\
1.48\end{array}$ & $\begin{array}{l}1.70 \\
1.89\end{array}$ & 1.78 & 1.47 & $1.73^{\mathrm{c}}$ & 2.00 \\
\hline Flux change $(\%)$ per $\%$ viscosity change & 0.54 & 0.78 & 0.9 & $\begin{array}{l}0.87 \\
0.87\end{array}$ & $\begin{array}{l}1.02 \\
1.12\end{array}$ & 1.00 & 1.1 & $0.88^{\mathrm{c}}$ & 1.06 \\
\hline Temp range of linearity $\left({ }^{\circ} \mathrm{C}\right)$ & $41-51$ & $32-54$ & $42-58$ & $\begin{array}{l}34-55 \\
36-55\end{array}$ & $\begin{array}{l}40-57 \\
39-52\end{array}$ & $33-49$ & $36-48$ & $33-37$ & $33-43$ \\
\hline Time range of linearity (h) & $0.5-3.7$ & $0.3-1$ & $0.5-2.7$ & $\begin{array}{l}0.25-2 \\
0.5-3\end{array}$ & $\begin{array}{l}0.5-1.5 \\
0.5-1.5\end{array}$ & $0.5-1.5$ & $0.5-2$ & $0.25-0.42$ & $0.5-1$ \\
\hline
\end{tabular}

${ }^{\mathrm{a}}$ Transmembrane pressure in bars

${ }^{\mathrm{b}}$ Prefiltered sample before 5-kDa membrane filtering

${ }^{\mathrm{c}}$ The time and temperature ranges were low for this sample, and the value should be considered approximate 

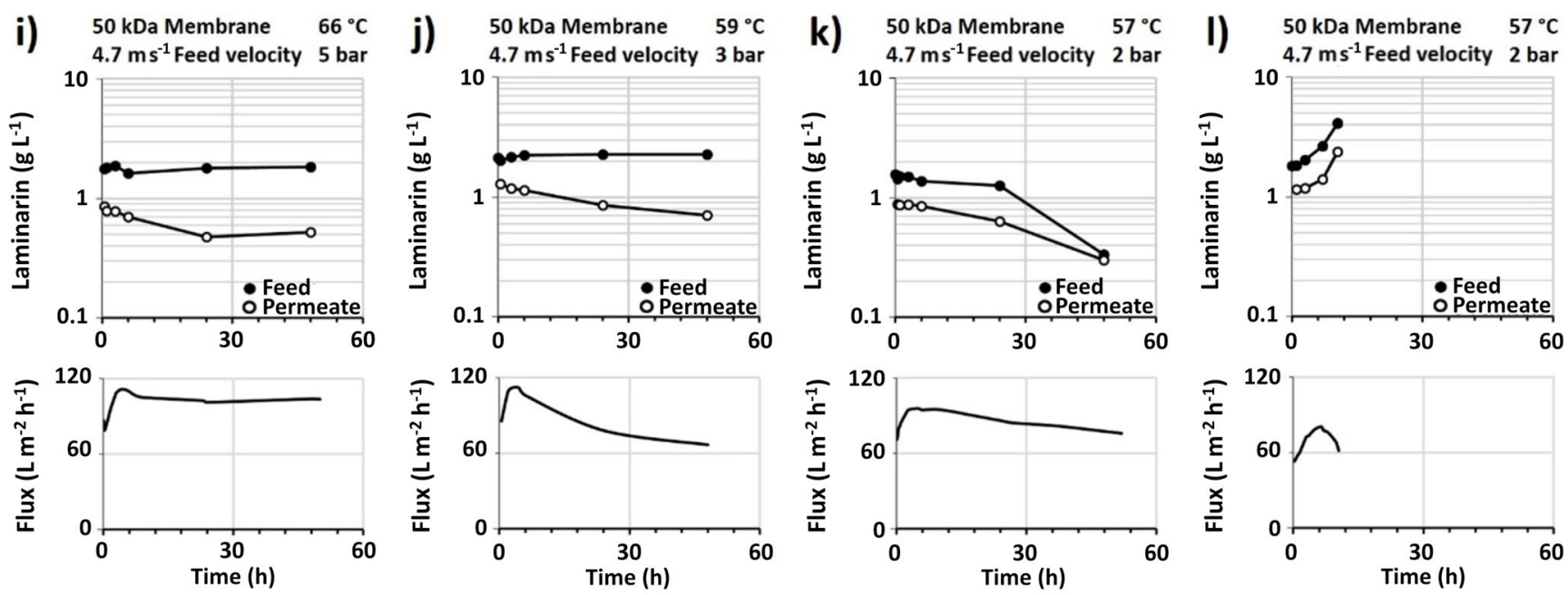

\begin{tabular}{|c|c|c|c|c|c|}
\hline & \multicolumn{3}{|c|}{ Laminarin passage ratio (\%): Permeate/feed } \\
\hline & i) & j) & k) & \multicolumn{2}{|c|}{ I) } \\
\hline $\mathbf{0 . 5}$ h & 48.5 & & 61.1 & \multicolumn{2}{|c|}{} \\
\hline $\mathbf{1 ~ h}$ & 43.5 & 63.7 & 57.2 & \multicolumn{2}{|c|}{63.0} \\
\hline $\mathbf{3 ~ h}$ & 41.5 & 54.8 & 58.6 & \multicolumn{2}{|c|}{57.7} \\
\hline $\mathbf{6}$ h & 43.2 & 50.9 & 62.1 & $\mathbf{7 ~ h}$ & 52.5 \\
\hline $\mathbf{2 4}$ h & 26.6 & 37.6 & 50.2 & $\mathbf{1 0 . 5} \mathbf{~ h}$ & 57.9 \\
\hline $\mathbf{4 8}$ h & 28.6 & 31.0 & 89.8 & & \\
\hline
\end{tabular}

\begin{tabular}{|c|c|c|c|c|c|}
\hline & \multicolumn{5}{|c|}{ Permeate Flux $\left(\mathbf{L ~ m}^{-\mathbf{2}} \mathbf{h}^{-\mathbf{1}}\right)$} \\
\hline & i) & j) & $\mathbf{k})$ & \multicolumn{2}{|c|}{$\mathbf{~ )}$} \\
\hline $\mathbf{0 . 5} \mathbf{h}$ & 81 & 86 & 80 & \multicolumn{2}{|c|}{54} \\
\hline $\mathbf{1} \mathbf{h}$ & 87 & & 84 & \multicolumn{2}{|c|}{58} \\
\hline $\mathbf{3} \mathbf{h}$ & 109 & 112 & 95 & \multicolumn{2}{|c|}{72} \\
\hline $\mathbf{6} \mathbf{h}$ & 110 & 106 & 95 & $\mathbf{7} \mathbf{h}$ & 78 \\
\hline $\mathbf{2 4} \mathbf{h}$ & 101 & 78 & 86 & $\mathbf{1 0 . 5} \mathbf{~}$ & 62 \\
\hline $\mathbf{4 8} \mathbf{h}$ & 104 & 67 & 78 & & \\
\hline
\end{tabular}
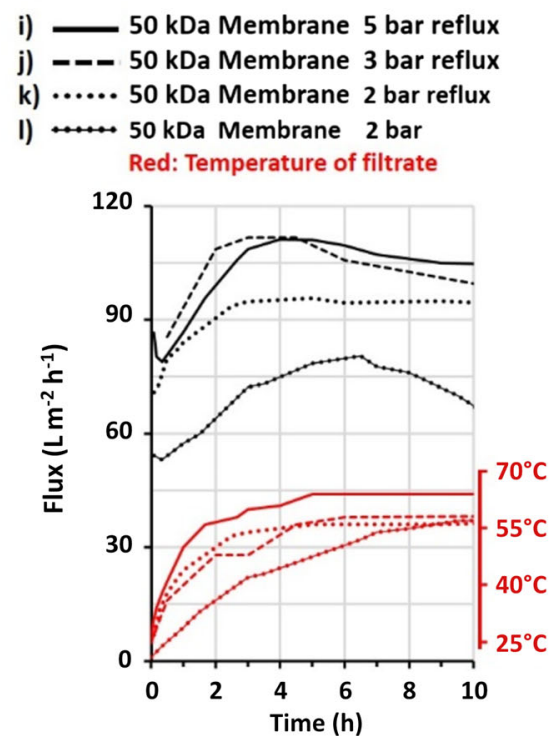

Fig. 4 Filtrations at a higher feed velocity with a 50-kDa membrane and varied pressure during filtration. $\mathbf{i}-\mathbf{k}$ have the permeate refluxed into the feed, while $\mathbf{I}$ has a sufficient volume to reach a steady state of $65 \mathrm{~L}$. Top plots: Laminarin concentration and permeate flux plotted versus the time of the filtration. The membrane $\mathrm{M}_{\mathrm{w}}$ cutoff, max temperature, feed velocity, and feed pressure are specified over each plot. The altered setting in i$\mathbf{k}$ is the feed pressure. $\mathbf{k}-\mathbf{l}$ are comparative filtration experiments - one

and succinic acids (seen by H-NMR but data not included). A very good signal of biological activity was the decrease of the compound mannitol, which is always present initially in the seaweed. Mannitol is a small enough molecule to pass through all the membranes unhindered, so the only reason that mannitol should change in concentration is degradation. Table 3 is a summary of the degradation of mannitol. For every filtration, the mannitol concentration was observed at the start and over time and fitted to an exponential function, and the average of the exponent was calculated. The average degradation of mannitol was approximately $2.2 \% \mathrm{~h}^{-1}$ for experiments with cooling and $8.6 \% \mathrm{~h}^{-1}$ for an experiment at higher temperatures and almost zero for samples that had been prefiltered. with the permeate refluxed back into the feed and one with a large but finite feed volume. Lower right plot: Permeate flux and temperature for the first $10 \mathrm{~h}$ of filtrations $\mathbf{i}-\mathbf{l}$. Straight, striped, dotted, and dotted straight lines are the curves of $\mathbf{i}-\mathbf{l}$, as indicated at the top of the plot. Tables: Values of the laminarin passage ratio and permeate flux for filtrations $\mathbf{i}-$ $\mathbf{I}$ at different times

\section{The effects of pressure and temperature on the flux}

A number of filtrations were performed with the reflux of the permeate back to the feed or with a large feed volume. The results of these filtrations show the long-time effects on membrane fouling but are also interesting in the start stages since the feed composition was more or less constant, while the temperature increased rapidly. To give a good overview, the permeate fluxes of the initial minimum, the maximum, and the "steady state" of $24 \mathrm{~h}$ are given for these filtrations with the temperature specified (Table 4). A normalized flux was calculated by first dividing the original permeate flux by the transmembrane pressure, which gave the flux as it would be 

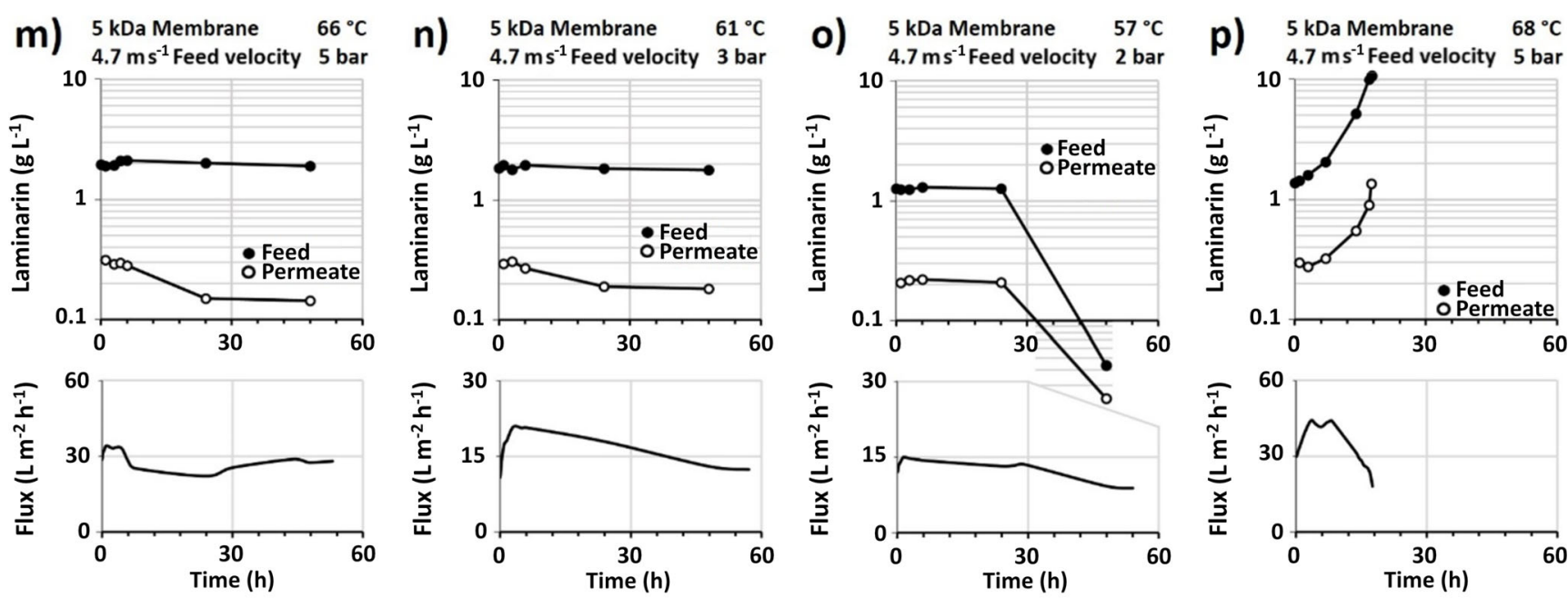

\begin{tabular}{|c|c|c|c|c|c|}
\hline & \multicolumn{5}{|c|}{ Laminarin passage ratio (\%): Permeate/feed } \\
\hline & m) & n) & o) & \multicolumn{2}{|c|}{ p) } \\
\hline $1 \mathrm{~h}$ & 16.4 & 15.0 & 16.6 & \multicolumn{2}{|c|}{20.8} \\
\hline $3 \mathrm{~h}$ & 15.0 & 17.2 & 17.5 & \multicolumn{2}{|c|}{17.2} \\
\hline $6 \mathrm{~h}$ & 13.3 & 13.7 & 17.0 & $7 \mathrm{~h}$ & 15.7 \\
\hline $24 \mathrm{~h}$ & 7.4 & 10.4 & 16.4 & $14 \mathrm{~h}$ & 10.7 \\
\hline $48 \mathrm{~h}$ & 7.5 & 10.2 & 54.0 & $17 \mathrm{~h}$ & 9.1 \\
\hline & & & & $17.5 \mathrm{~h}$ & 12.6 \\
\hline
\end{tabular}

\begin{tabular}{|c|c|c|c|c|c|}
\hline & \multicolumn{4}{|c|}{ Permeate Flux $\left(\mathbf{L ~ m}^{-\mathbf{2}} \mathbf{h}^{-\mathbf{}}\right)$} \\
\hline & $\mathbf{m})$ & $\mathbf{n})$ & o) & \multicolumn{2}{|c|}{ p) } \\
\hline $\mathbf{1} \mathbf{h}$ & 32 & 15 & 14 & \multicolumn{2}{|c|}{34} \\
\hline $\mathbf{3} \mathbf{h}$ & 34 & 18 & 14 & \multicolumn{2}{|c|}{43} \\
\hline $\mathbf{6} \mathbf{h}$ & 33 & 21 & 15 & $\mathbf{7 h}$ & 43 \\
\hline $\mathbf{2 4} \mathbf{h}$ & 28 & 21 & 14 & $\mathbf{1 4 h}$ & 31 \\
\hline $\mathbf{4 8} \mathbf{h}$ & 22 & 18 & 13 & $\mathbf{1 7 h}$ & 23 \\
\hline & & & & $\mathbf{1 7 . 5 h}$ & 18 \\
\hline
\end{tabular}

Fig. 5 Filtrations at a higher feed velocity with a 5-kDa membrane and varied pressure during filtrations. $\mathbf{m}-\mathbf{o}$ have the permeate refluxed into the feed, while $\mathbf{p}$ has a sufficient volume to reach a steady state at $55 \mathrm{~L}$. The feed for $\mathbf{p}$ was prefiltered with a $50-\mathrm{kDa}$ membrane before that filtration. Top plots: Laminarin concentration and permeate flux plotted versus the time of filtration. The membrane $\mathrm{M}_{\mathrm{w}}$ cutoff, max temperature, feed velocity, and feed pressure are specified over each plot. The altered setting in $\mathbf{m}-\mathbf{p}$ is the feed pressure. $\mathbf{0}-\mathbf{p}$ are comparative filtration

for an equally blocked membrane but with a transmembrane pressure of 1 bar (pressure-normalized flux). As the next step, the pressure-normalized flux was divided by the dynamic viscosity of water at $20{ }^{\circ} \mathrm{C}\left(1 \mathrm{~mm}^{2} \mathrm{~s}^{-1}\right)$ and multiplied by the dynamic viscosity of water at the temperature of the measurement, which gave the permeate flux that would result if the feed temperature was $20^{\circ} \mathrm{C}$ and the transmembrane pressure was $1 \mathrm{bar}$. The logic behind this is that since our feed is a dilute low viscous solution, the viscosity depends linearly on the viscosity of water, while the permeate flux is inversely proportional to the viscosity of the feed. When the viscosity was measured between $14{ }^{\circ} \mathrm{C}$ and $37{ }^{\circ} \mathrm{C}$ for our solution, presented in Table 2, this linear relation between pure water m) $5 \mathrm{kDa}$ Membrane 5 bar reflux

n) - - 5 kDa Membrane 3 bar reflux

o) ...... $5 \mathrm{kDa}$ Membrane 2 bar reflux

p) .... $5 \mathrm{kDa}$ after $50 \mathrm{kDa} 5 \mathrm{bar}$ Red: Temperature of filtrate

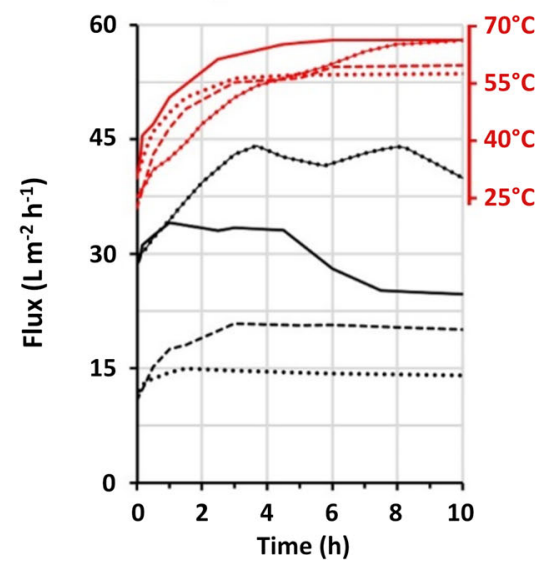

experiments - one with the permeate refluxed back into the feed and one with a large but finite feed volume. Additionally, $\mathbf{p}$ is prefiltered, while $\mathbf{o}$ is not. Lower right plot: Permeate flux and temperature for the first $10 \mathrm{~h}$ of filtrations $\mathbf{m}-\mathbf{p}$. Straight, striped, dotted, and dotted straight lines are the curves of $\mathbf{m}-\mathbf{p}$, as indicated at the top of the plot. Tables: Values of the laminarin passage ratio and permeate flux for filtrations $\mathbf{m}-$ $\mathbf{p}$ at different times.

viscosity and the viscosity of our solution was true to $1.5 \%$ accuracy, and the viscosity of our solution was 1.208 times higher than of pure water.

Normalized permeate flux $=\frac{\text { permeate flux }}{\text { transmembrane pressure }}$

$$
\times \frac{\mathrm{H}_{2} \mathrm{O} \text { visc. at } 20^{\circ} \mathrm{C}}{\mathrm{H}_{2} \mathrm{O} \text { visc. at temp }}
$$

From the results of the normalized permeate flux (Table 4), it is seen that for all filtrations, while the flux increased from the minimum at the start of the filtration to the maximum value 

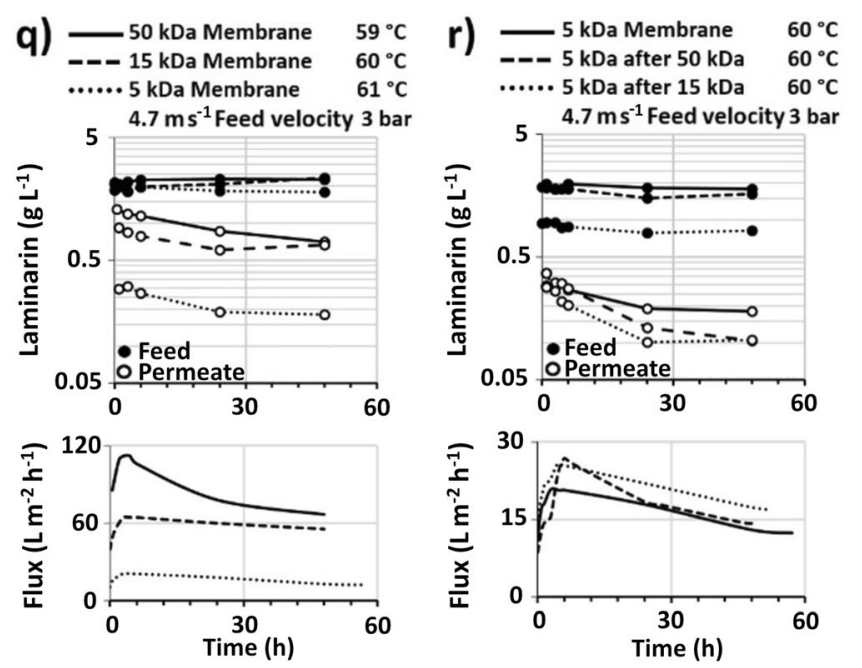

\begin{tabular}{|c|c|c|c|c|c|c|}
\hline & \multicolumn{6}{|c|}{ Laminarin passage ratio (\%): Permeate/feed } \\
\hline & $\begin{array}{c}\text { q) } \\
50 \mathrm{kDa}\end{array}$ & $\begin{array}{c}\text { q) } \\
15 \mathrm{kDa}\end{array}$ & $\begin{array}{c}\text { q) } \\
5 \mathrm{kDa}\end{array}$ & $\begin{array}{c}\text { r) } \\
5 \mathrm{kDa}\end{array}$ & $\begin{array}{l}\text { r) after } \\
15 \mathrm{kDa}\end{array}$ & $\begin{array}{l}\text { r) after } \\
50 \mathrm{kDa}\end{array}$ \\
\hline $1 \mathrm{~h}$ & 63.7 & 43.9 & 15.0 & 15.0 & 38.6 & 15.6 \\
\hline $3 \mathrm{~h}$ & 54.8 & 46.1 & 17.2 & 17.2 & 27.8 & 17.5 \\
\hline $6 \mathrm{~h}$ & 50.9 & 39.7 & 13.7 & 13.7 & 23.0 & 15.5 \\
\hline $24 \mathrm{~h}$ & 37.6 & 29.1 & 10.4 & 10.4 & 12.9 & 8.8 \\
\hline $48 \mathrm{~h}$ & 31.1 & 28.4 & 10.2 & 10.2 & 12.9 & 6.4 \\
\hline
\end{tabular}

Fig. 6 Compilation of long-term filtrations to enable visual comparison of the effects of $\mathbf{r}$ different membrane $\mathrm{M}_{\mathrm{w}}$ cutoffs, $\mathbf{q}$ direct filtration with 5-kDa $\mathrm{M}_{\mathrm{w}}$ cutoff membranes and similar filtration with the prefiltering through a membrane with a $50 \mathrm{kDa}$ or $15 \mathrm{kDa} \mathrm{M}_{\mathrm{w}}$ cutoff and $\mathbf{s}-\mathbf{t}$ microbial degradation after long filtration times in cold and hot conditions. Top plots: Laminarin concentration and permeate flux plotted versus the time

in the early hours of the filtration, the normalized flux decreased and after $24 \mathrm{~h}$ it decreased further.

At the specific interval when the temperature of the feed and, thus, the permeate flux increased very rapidly, there was a faster flux increase than the flux decrease due to membrane fouling or changes in the gel layer. This interval was called the range of linearity. A linear trend line was fitted to the data within the range to calculate the percent impact of a $1{ }^{\circ} \mathrm{C}$ temperature change or, similarly, a $1 \%$ viscosity change of the feed (Table 4). A $1 \%$ decrease in the feed viscosity resulted in an approximately $1 \%$ increase in the permeate flux.

\section{Changes in molecular weight and SEC data}

As seen in Fig. $7 \mathrm{a}$, the majority of laminarin is found in one peak at around $9 \mathrm{kDa}$ (peak II), which was seen by running fractions from the SEC by NMR, this from a sample in which the laminarin content had been concentrated in the feed by filtering through a $5-\mathrm{kDa}$ membrane for $63 \mathrm{~h}, 10-13^{\circ} \mathrm{C}$, and to one-third of the original feed volume. It is also seen that peak II has a smaller extra peak. The composition of the extra peak was not identified but it was found that this peak went through the $5-\mathrm{kDa}$ membrane at a higher
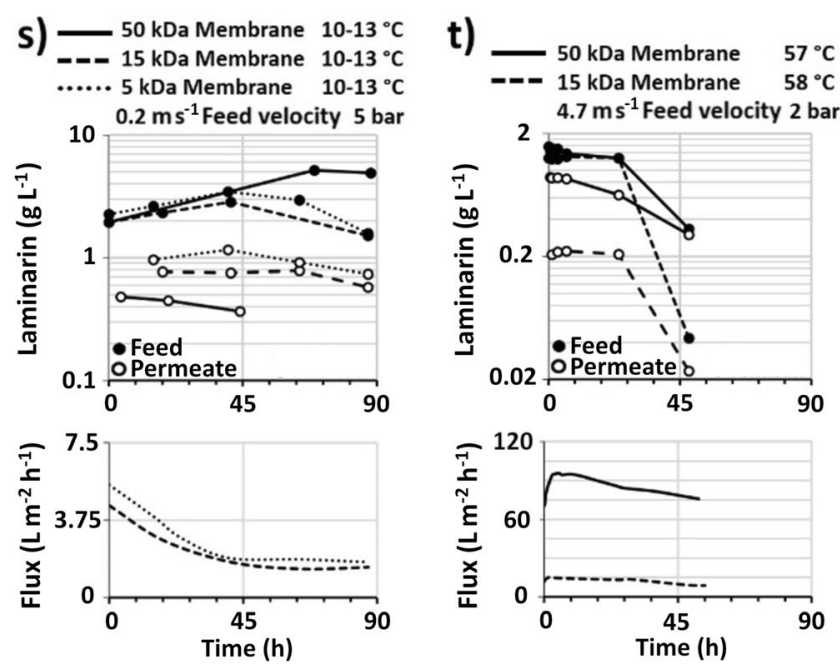

\begin{tabular}{|c|c|c|c|c|c|c|}
\hline & \multicolumn{6}{|c|}{ Permeate Flux $\left(\mathrm{L} \mathrm{m}^{-2} \mathrm{~h}^{-1}\right)$} \\
\hline & $\begin{array}{c}\text { q) } \\
50 \mathrm{kDa}\end{array}$ & $\begin{array}{c}\text { q) } \\
15 \mathrm{kDa}\end{array}$ & $\begin{array}{c}\text { q) } \\
5 \mathrm{kDa}\end{array}$ & $\begin{array}{c}\text { r) } \\
5 \mathrm{kDa}\end{array}$ & $\begin{array}{l}\text { r) after } \\
15 \mathrm{kDa}\end{array}$ & $\begin{array}{l}\text { r) after } \\
50 \mathrm{kDa}\end{array}$ \\
\hline $1 \mathrm{~h}$ & 86 & 48 & 15 & 15 & 11 & 18 \\
\hline $3 \mathrm{~h}$ & & 54 & 18 & 18 & 13 & 20 \\
\hline $6 \mathrm{~h}$ & 112 & 65 & 21 & 21 & 16 & 23 \\
\hline $24 \mathrm{~h}$ & 106 & 65 & 21 & 21 & 27 & 25 \\
\hline $48 \mathrm{~h}$ & 78 & 60 & 18 & 18 & 18 & 22 \\
\hline
\end{tabular}

of the filtration. The membrane $\mathrm{M}_{\mathrm{w}}$ cutoff, max temperature, feed velocity, and feed pressure are specified over each plot q-t. For each of plots $\mathbf{q}-\mathbf{t}$, the feed velocity and feed pressure are indicated just over the plot, while the settings that are unique to each filtration are next to straight, striped, and dotted lines over the plots. Tables: Values of the laminarin passage ratio and permeate flux for filtrations $\mathbf{q}$ and $\mathbf{r}$

percentage than laminarin, giving that after longer concentration experiments, it was reduced in comparison to laminarin. This is clearly shown in Fig. $7 \mathrm{a}_{\mathrm{ii}}$, when a sample was concentrated to one-third of its volume twice, with a refill of water in between and over the course of 63 and $72 \mathrm{~h}$, making the extra peak almost disappear. In Fig. $7 \mathrm{a}_{\mathrm{iii}}$, the change in peak shape of peak II in the permeate of the different membranes is visualized, showing both a decrease in peak area and a position at slightly lower $\mathrm{M}_{\mathrm{w}}$. In Fig. $7 \mathrm{~b}$, the ratio of permeate vs feed for $\mathrm{M}_{\mathrm{w}}$ and area of peak II is presented. The $\mathrm{M}_{\mathrm{w}}$ in the permeate decreased compared to the feed with ratios down to around $60 \%$ for the extended filtrations with permeate reflux. In Fig. 7 b, data are presented for the ratio of peak area II between permeate and feed, and the ratio of laminarin between permeate and feed was previously determined by NMR (laminarin passage ratio). The values of these ratios followed each other rather well. In total, also including the filtrations now shown in Fig. $7 \mathrm{~b}$, the difference of peak area II ratio minus laminarin passage ratio for 50-, $15-$, and 5-kDa membranes was $4.0 \pm 3.6 \%(n=22),-0.3 \% \pm$ $4.9 \%(\mathrm{n}=8)$, and $-3.3 \% \pm 4.9 \%(n=15)$ (where $n$ is the number of compared pairs of ratios and \pm the standard deviation).

The peak with the highest $\mathrm{M}_{\mathrm{w}}$ compounds, peak I, decreased in molecular weight during the course of the filtrations 
a)

Concentration of laminarin in feed at $5 \mathrm{bar}, 0.2 \mathrm{~m} \mathrm{~s}^{-1}, 10-13^{\circ} \mathrm{C}$
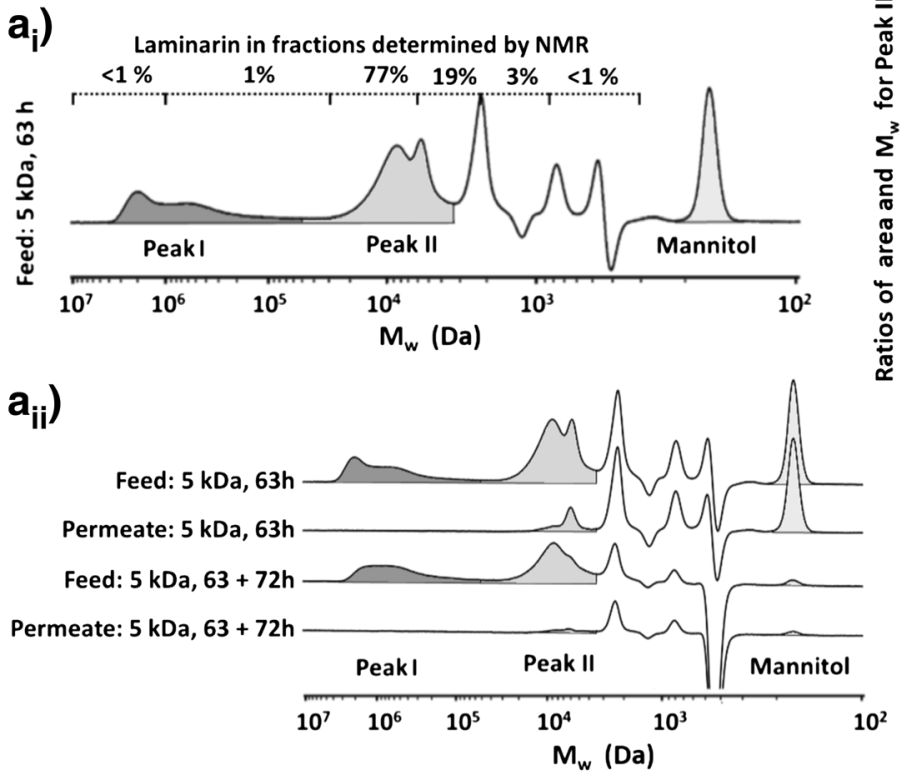

Permeate reflux at 3 bar, $4.7 \mathrm{~m} \mathrm{~s}^{-1}, \sim 60^{\circ} \mathrm{C}$

$\mathbf{a}_{\mathrm{iii}}$ )

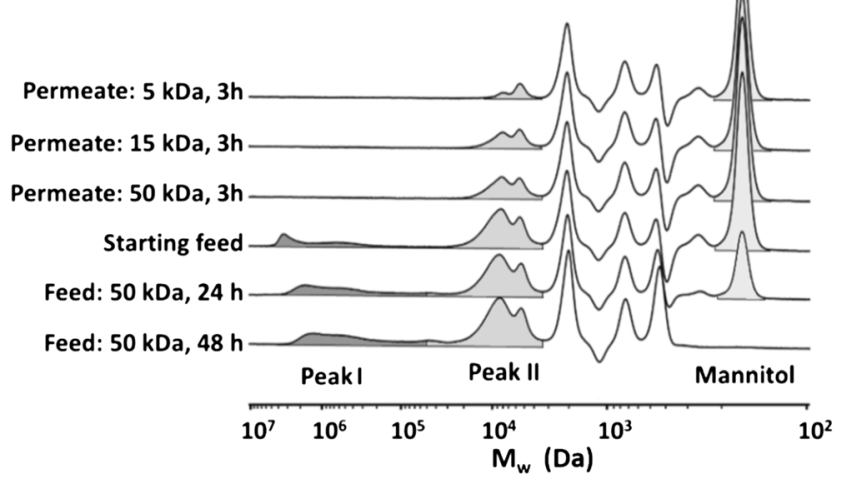

Fig. 7 a Peak I-II in SEC chromatograms for some filtrations. $M_{w}$ marks on the axis are calculated from a pullulan standard calibration curve. Shown sections are from 14 to $34 \mathrm{~min}$ out of $40 \mathrm{~min}$. $\mathbf{a}_{\mathbf{i}-\mathrm{i} i}$ filtrations with a $5-\mathrm{kDa}$ membrane in which laminarin becomes concentrated in the feed. $\mathbf{a}_{\mathbf{i}}$ One sample fractionated by SEC to measure laminarin by NMR (Size exclusion chromatography). $\mathbf{a}_{\mathbf{i i}}$ Feed and permeate after a filtration with feed volume reduced to $1 / 3$, taking $63 \mathrm{~h}$, and the repeated procedure taking $72 \mathrm{~h}$, after refilling with water between. $\mathbf{a}_{\text {iii }}$ Filtrations with permeate reflux. b Ratio between feed and permeate for peak II, $\mathrm{M}_{\mathrm{w}}$,

(Fig. $7 \mathrm{a}_{\text {iii }}$ ) for reflux filtrations at $3 \mathrm{bar}, 4.7 \mathrm{~m} \mathrm{~s}^{-1}$ feed velocity, and temperature around $60{ }^{\circ} \mathrm{C}$. The trend of the $\mathrm{M}_{\mathrm{w}}$ over time for peaks I-II is plotted in Fig. $7 \mathrm{c}$. The $\mathrm{M}_{\mathrm{w}}$ of the heavier fraction of peak I decreased, while that $\mathrm{M}_{\mathrm{w}}$ of peak II increased slightly for the extended filtrations with permeate reflux, higher feed velocity, and temperature. Likely the increase is related to molecules from the fraction with higher molecular weight that degrade or disrupt so that they end up in the same size range as peak II. The $\mathrm{M}_{\mathrm{w}}$ of peak II at the start of filtration was on average $9.13 \pm 0.49 \mathrm{kDa}$ for 20 samples. The
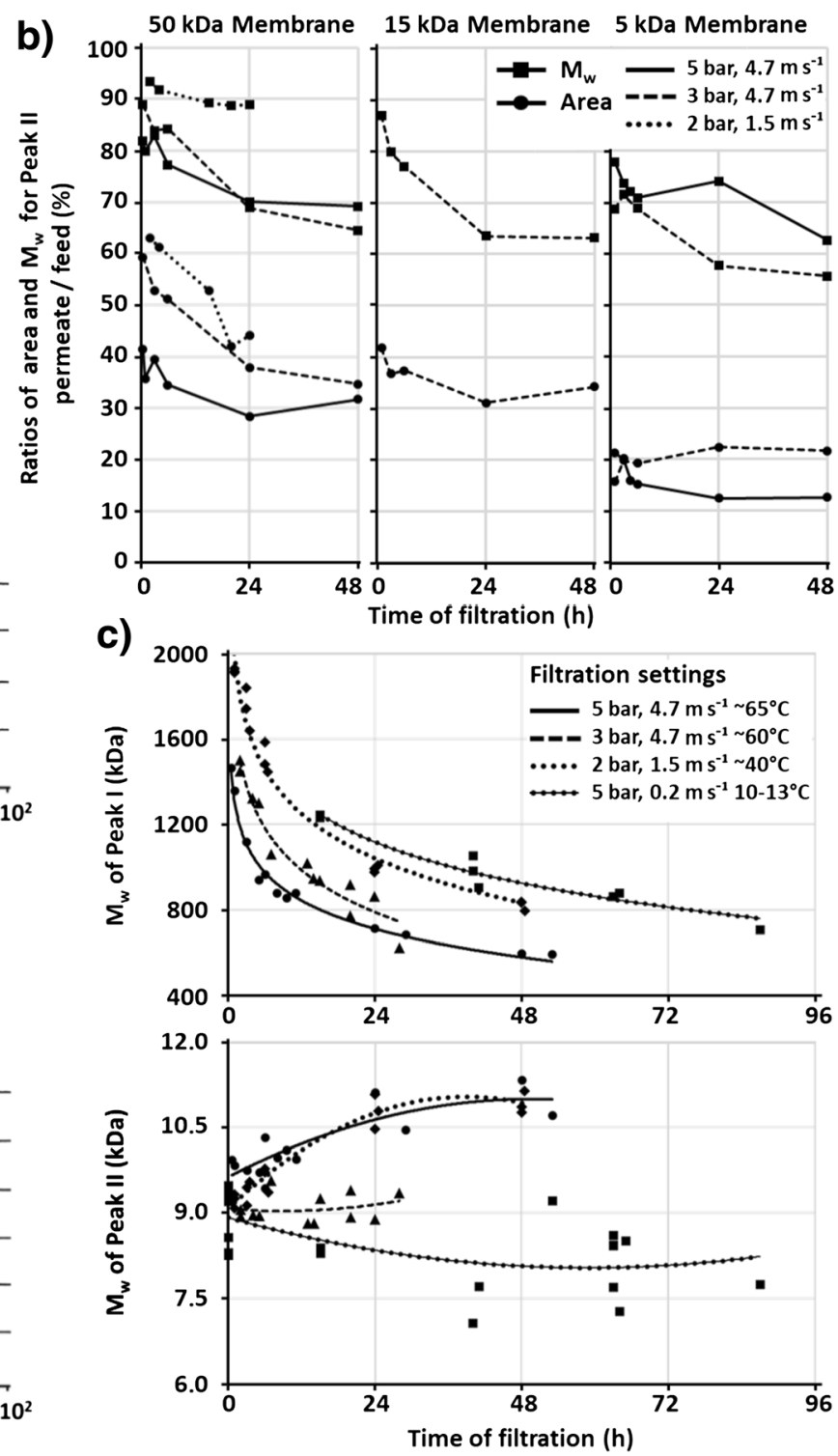

and peak area for some examples of a filtrations. $\mathrm{c}_{\mathrm{w}}$ for peak I-II over time of filtration. Peak I was measured in the feed. Peak II was measured in the feed for permeate reflux filtrations $\left(4.7 \mathrm{~m} \mathrm{~s}^{-1}\right.$ feed velocity) and as average $M_{w}$ for the rest. The average $M_{w}$ was calculated for the total sum of molecules in II, by also accounting for the difference in the volume of and concentration (peak area) in feed and gathered permeate. The trend lines of $\mathbf{c}$ are of log-linear regression with time as $\log$ scale for peak I and of second-order polynomial regression for peak II.

$\mathrm{M}_{\mathrm{w}}$ of peak II of Fig. $7 \mathrm{a}_{\mathrm{ii}}$ from which the extra peak was almost removed had a $\mathrm{M}_{\mathrm{w}}$ of $9.7 \mathrm{kDa}$.

\section{Discussion}

\section{Initial tests}

Regarding the initial tests on fresh and frozen biomass (beginning of Cross-flow filtration study), the amounts of extracted 
compounds varied between the two different batches of frozen biomass. That laminarin content varies greatly with the season and growth site is a known trait and was expected (Black 1950; Schiener et al. 2015). That great difference in extracted laminarin between fresh and frozen biomass, with almost ten times as much laminarin coming from the frozen biomass is a factor to consider if a similar disruption technique as ours is to be used. This is probably since freezing helps break cell walls and make homogenization and extraction easier. That neither changing the time and temperature of the laminarin extraction step nor changing to a technique with sodium carbonate-based dissolution of the freeze-dried and powdered seaweed managed to extract more laminarin is the reason to believe that our laminarin dissolution was extracting a major part of the laminarin.

\section{Cross-flow filtration}

The higher feed velocity of $4.7 \mathrm{~m} \mathrm{~s}^{-1}$ as compared to $1.7 \mathrm{~m} \mathrm{~s}^{-1}$ or $0.2 \mathrm{~m} \mathrm{~s}^{-1}$ was beneficial for all filtrations since it increased the permeate flux, especially in the long run, by reducing membrane fouling (Filtrations with a lower feed velocity and cooling, Filtrations with a higher feed velocity, The effect of pressure on $50-\mathrm{kDa}$ filtrations (with reflux circulation or a high initial volume), The effect of pressure on $5-\mathrm{kDa}$ filtrations (with reflux circulation or a high initial volume)).

For the pre-filtrations with the 50-kDa membrane, the lower feed pressure of 2 bar was preferred since it gave the highest laminarin passage ratio and since increasing the pressure did not increase the permeate flux much. A good permeate flux at this setting was $60-80 \mathrm{~L} \mathrm{~m}^{-2} \mathrm{~h}^{-1}$ at approximately $60^{\circ} \mathrm{C}$ (The effect of pressure on 50-kDa filtrations (with reflux circulation or a high initial volume)). The reason to choose a lower pressure is that even though a higher pressure such as 5 bar increase the permeate flux, it also reduces the laminarin passage ratio, and as seen on the comparably low value on pressure/ temperature-normalized permeate flux (at max: 10.8 and 24.3 $\mathrm{L} \mathrm{m}^{-2} \mathrm{~h}^{-1}$, for 5 and 2 bar), meaning that the energy demanding buildup of pressure has low effect on the flux (The effects of pressure and temperature on the flux). (In the ideal case, the buildup of double the pressure requires double the energy.)

On the contrary for the filtrations with the $5-\mathrm{kDa}$ membrane, the higher feed pressure of 5 bar was preferred since it gave the lowest laminarin passage ratio and did increase the permeate flux substantially. A good permeate flux through the membrane at this setting was $30-40 \mathrm{~L} \mathrm{~m}^{-2} \mathrm{~h}^{-1}$ at approximately $65^{\circ} \mathrm{C}$ (The effect of pressure on 5-kDa filtrations (with reflux circulation or a high initial volume)), and in this case, the pressure/temperature-normalized permeate flux was more similar between filtrations at high and low pressure (at max: 3.9 and $4.6 \mathrm{~L} \mathrm{~m}^{-2} \mathrm{~h}^{-1}$, for 2 and 5 bar), meaning a more efficient use of the built of pressure (The effects of pressure and temperature on the flux). The laminarin passage ratio became approximately $10 \%$ when the $5-\mathrm{kDa}$ membrane was used at 5 bar feed pressure. A membrane with an even lower $\mathrm{M}_{\mathrm{w}}$ cutoff could decrease the lost amount further, but this would be a trade-off since it would also decrease the permeate flux.

In theory, since laminarin is a range of different sized molecules, the decrease in laminarin passage ratio over should decrease more in filtrations without permeate reflux since the low $\mathrm{M}_{\mathrm{w}}$ end of the fraction that can pass the membrane decreases with time. The decrease in $\mathrm{M}_{\mathrm{w}}$ of the permeate compared to the feed was seen (Changes in molecular weight and SEC data), but when comparing the passage ratio over time between experiments with and without permeate refluxing, there was no indication that the laminarin passage ratio should decrease more in filtrations without the permeate refluxing. Possibly this effect is small and overshadowed by differences in membrane fouling that change passage ratio during the course of longer filtrations.

Microbial degradation affected the feed during longer filtrations and could eventually consume the laminarin in the feed. The microbial activity was most easily studied by the decrease in the mannitol concentration during the filtrations and in no case was the laminarin visibly decreased before the mannitol was consumed (Filtrations with previously filtered samples and signs of biological activity). At the higher temperatures of $37-66^{\circ} \mathrm{C}$, the mannitol concentration decreased by $\sim 8.6 \% \mathrm{~h}^{-1}$, while for the filtrations with cooling (10-13 ${ }^{\circ} \mathrm{C}$ ), it decreased by $\sim 2.3 \% \mathrm{~h}^{-1}$. Prefiltering reduced the mannitol consumption greatly, just as cooling did. Cooling is energy demanding in itself and as well temperature has a positive effect on the permeate flux which makes the process go quicker and become more energy efficient. With increased temperatures, the permeate flux increased since the viscosity of the feed decreased. Upon a fast temperature change, a decrease in viscosity of $1 \%$ (for pure water assumed to be proportional to the feed viscosity) roughly resulted in an increase of the permeate flux by $1 \%$ (The effects of pressure and temperature on the flux). With this in mind if possible, a more efficient way of performing filtrations is to increase the temperature further and by doing so also reducing the chances of microbial degradation, and as long as the targeted molecule resist the temperature get a more efficient process.

To check whether thermal or microbial activity degraded laminarin its $\mathrm{M}_{\mathrm{w}}$ over time was measured by SEC (Changes in molecular weight and SEC data). Our laminarin samples were measured to $9 \mathrm{kDa}$ in $\mathrm{M}_{\mathrm{w}}$, but in a peak that included a small overlapping extra peak so it should be considered approximate value. Laminarin, as most $(1,3)$ - $\beta$-glucans, is a stiffer molecule than pullulan, that was used as SEC standard, which makes laminarin occupy a larger hydrodynamic volume than pullulan and have its $\mathrm{M}_{\mathrm{w}}$ somewhat overestimated by the SEC (Gidley and Nishinari 2009). In other studies, laminarin is also often determined to slightly lower $\mathrm{M}_{\mathrm{w}}$ values, such as 3-5 
kDa (Rinaudo 2007) or 4-6 kDa (Stone 2009). However, both laminarin and pullulan occupy a larger hydrodynamic volume than the more globular molecules (typically dextran or proteins) that are used for calibration of the ceramic membranes, meaning that they pass the membrane to a lower degree than the molecule of which the $\mathrm{M}_{\mathrm{w}}$ cutoff refers to (Ripperger et al. 2013). The substance, that showed up as a small extra peak that overlapped the laminarin peak in the SEC chromatograms, was more prone to pass the $5-\mathrm{kDa}$ membrane compared to laminarin, seen as a gradual decrease in its concentration relative to laminarin in the feed during filtrations with $5-\mathrm{kDa}$ membrane. The laminarin containing fraction showed no sign of decreasing in $\mathrm{M}_{\mathrm{w}}$ over time but instead increased a little. The increase can be related to the fact that the fraction with the highest $\mathrm{M}_{\mathrm{w}}$ decreased in $\mathrm{M}_{\mathrm{w}}$ and that the fragments of larger molecules joined in with the fraction containing laminarin. That fractions of higher $\mathrm{M}_{\mathrm{w}}$ compounds get degraded can possibly have a positive effect on filtrations since larger molecules drive the membrane fouling in these filtrations (Bhave 1996); however, if these fragments join in with the laminarin fraction, it could complicate the final purification of the product. In the filtrations at the highest pressure and temperature, an increase in permeate flux at the end of the filtrations was observed (The effect of pressure on $5-\mathrm{kDa}$ filtrations (with reflux circulation or a high initial volume)) which could indicate that thermal (or shear) induced changes in the feed make it easier to filter. The final step of purification was not investigated in this study.

\section{Comparison to other studies}

A few publications and three patents can be found in which cross-flow filtration is suggested for the concentration of laminarin. In a patent by Yvin et al. (1998), a 5-kDa membrane is used for the concentration of laminarin. In a patent by Yvin et al. (1999) a 50-kDa membrane is used for pre-filtration and a $0.5-1-\mathrm{kDa}$ membrane is used for the concentration of laminarin, and in a patent Hjelland et al. (2-12), a membrane with $\mathrm{M}_{\mathrm{W}}$ cutoff of $10 \mathrm{kDa}$ or greater is used for prefiltering and a membrane with $\mathrm{M}_{\mathrm{w}}$ cutoff of $1 \mathrm{kDa}$ or smaller is used for laminarin concentration (Yvin et al. 1998, 1999; Hjelland et al. 2012). In a paper by Klarzynski et al. (2000), a 300$\mathrm{kDa}$ membrane is used for pre-filtration and a $1-\mathrm{kDa}$ membrane is used for the concentration of laminarin. In a paper by Becker et al. (2020), laminarin from microalgae is concentrated using a $1-\mathrm{kDa}$ membrane while laminarin is also consumed by microorganisms during the process.

Besides describing the filtration membranes used, we found no paper or patent that describe the cross-flow filtration for the concentration of laminarin in terms of filtration settings, permeate flux, or laminarin passage/retention ratio. The comparisons are done versus studies that that have similar $\mathrm{M}_{\mathrm{w}}$ cutoff span (5-50 kDa), similar $\mathrm{ZrO}_{2} / \mathrm{TiO}_{2}$ surface structure as the Kerasep filter in this study are used and similar low viscous water-based feed solutions as in our study. These studies are found in Table 5 . When using a high feed velocity $\left(4.7 \mathrm{~m} \mathrm{~s}^{-1}\right)$ for pre-filtration of our extract solutions (by using a 50 - or $15-\mathrm{kDa}$ membrane), the permeate fluxes at comparable temperature correspond fairly well to the fluxes for clarification of apple juice (Table 5. Ref. D) and filtration of vanillin lignin solutions for the 50-kDa membranes (Table 5. Ref. C) for the $50-\mathrm{kDa}$ membrane, but our studies permeate flux values are lower than that of filtering oligosaccharides from caprine milk (Table 5. Ref. B). The trend when filtering our feed solution was that the permeate flux was higher with a 50$\mathrm{kDa}$ membrane compared to a $15-\mathrm{kDa}$ membrane, but seemingly with other feed such as the feed composed of lignin and vanillin in (Table 5. Ref. C), it was instead lower. As a general rule and in most studies, the choice of a membrane with greater $\mathrm{M}_{\mathrm{w}}$ cutoff was however increasing the permeate flux. At the low feed velocity $\left(0.2 \mathrm{~m} \mathrm{~s}^{-1}\right)$, our extract solution got a lower permeate flux than that of apple juice, with comparable settings (Table 5. Ref. A). The separation of laminarin with the 5$\mathrm{kDa}$ membrane can be compared to that of filtrating xylan oligosaccharides from rice husk autohydrolysis product since these were also polysaccharides of low $\mathrm{M}_{\mathrm{w}}, 1-3 \mathrm{kDa}$ (Table 5 . Ref. E). With the lower $\mathrm{M}_{\mathrm{w}}$ in mind, the comparison between our results and the results of xyloglucan hydrolysis product, $7-16 \%$ vs $30 \%$ passage ratio, is reasonable. The permeate flux of the xyloglucan hydrolysis product was comparatively higher than in this paper which, when they were also using a lower temperature during the filtration. When comparing to a study in which Kerasep membranes were used as in our study, in which a model lignin degradation product is filtered, our permeate flux is also comparatively lower for the $5-\mathrm{kDa}$ membrane, both when comparing our high and low feed velocity results (Table 5. Ref. F).

\section{Summary and conclusion}

In conclusion, laminarin can be concentrated from the solution from the acid pretreatment of homogenized Saccharina latissima seaweed using cross-flow filtration as the method. Based on the filtrations in the study, a good method is to prefilter through a $50-\mathrm{kDa}$ membrane at a high feed velocity of $\sim 5 \mathrm{~m} \mathrm{~s}^{-1}$ and a low feed pressure of 2 bar and use the permeate from that filtration as the feed for a $5-\mathrm{kDa}$ membrane filtration. In the $5-\mathrm{kDa}$ membrane filtration, the laminarin is concentrated in the feed, and it should have a high feed velocity of $\sim 5 \mathrm{~m} \mathrm{~s}^{-1}$ and a high feed pressure of 5 bar. With these settings, the laminarin passage ratio began at $15 \%$ but reached $7 \%$ after $24 \mathrm{~h}$ of filtration with a $5-\mathrm{kDa}$ membrane. The laminarin $\mathrm{M}_{\mathrm{w}}$ was determined approximately to $9 \mathrm{kDa}$ which motivates the use of a $5-\mathrm{kDa}$ membrane to retain the majority of the product. Cooling the filtrations decreased the microbial 
อั

๕ั)

ڤे

䔩

성

T.

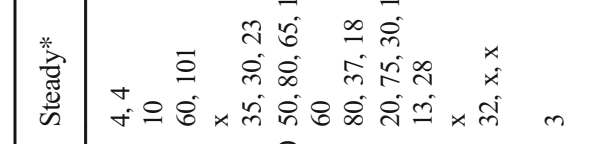

ఫั่

胥

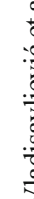
2

$$
\ddot{4}
$$$$
\text { 政 }
$$$$
\text { 离, }
$$

逮

:

眞

总 문

蒙告

峁

혀

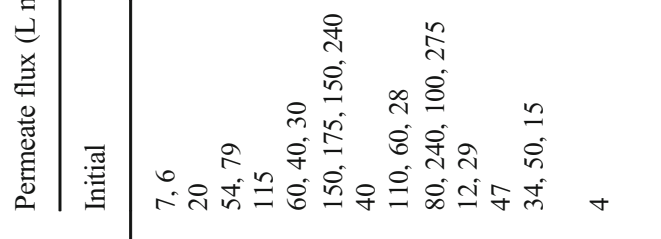
(

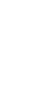

言 
degradation of the feed while filtrating but also made the filtration go slower which makes us not recommend it. Instead, the increase of the permeate flux with temperature and the fact that laminarin showed no detectable sign of thermal degradation motivates testing and increasing the temperature even further.

Acknowledgments Open Access funding provided by Royal Institute of Technology. Simon Johansson, Jonatan Gerrbo, Gunnar Cervin, Göran Nylund, and Henrik Pavia at the KosterAlg AB/Sven Lovén Center for Marine Sciences (Gothenburg University) are thanked for cultivating and donating the Saccharina latissima seaweed. Oskar Schmidt, KTH Alumni, is thanked for sharing his expertise on the cross-flow filtration technique. Mikael Lindström, Dean of School of Engineering Sciences in Chemistry, Biotechnology, and Health at $\mathrm{KTH}$, is thanked for allowing us to use his cross-flow filtration setup.

Funding The Swedish research council FORMAS is acknowledged for funding this research and the Seafarm project (Grant number 2013-92).

\section{Declarations}

Conflict of interest The authors declare no conflict of interest.

Open Access This article is licensed under a Creative Commons Attribution 4.0 International License, which permits use, sharing, adaptation, distribution and reproduction in any medium or format, as long as you give appropriate credit to the original author(s) and the source, provide a link to the Creative Commons licence, and indicate if changes were made. The images or other third party material in this article are included in the article's Creative Commons licence, unless indicated otherwise in a credit line to the material. If material is not included in the article's Creative Commons licence and your intended use is not permitted by statutory regulation or exceeds the permitted use, you will need to obtain permission directly from the copyright holder. To view a copy of this licence, visit http://creativecommons.org/licenses/by/4.0/.

\section{References}

Aziz A, Poinssot B, Daire X, Adrian M, Bézier A, Lambert B, Joubert JM, Pugin A (2003) Laminarin elicits defense responses in grapevine and induces protection against Botrytis cinerea and Plasmopara viticola. Mol Plant-Microbe Interact 16:1118-1128

Becker S, Tebben J, Coffinet S, Wiltshire K, Iversen MH, Harder T, Hinrichs KU, Hehemann JH (2020) Laminarin is a major molecule in the marine carbon cycle. Proc Natl Acad Sci USA 117:65996607

Bhave RR (1996) Cross-Flow Filtration. In: Fermentation and biochemical engineering handbook, 2nd edn. William Andrew Publishing, New Jersey, pp 271-347

Black WAP (1950) The seasonal variation in weight and chemical composition of the common British Laminariaceae. J Mar Biol Assoc U K 29:45-72

Black WAP, Cornhill WJ, Dewar ET, Woodward FN (1951) Manufacture of algal chemicals. III. Laboratory-scale isolation of laminarin from brown marine algae. J Appl Chem 11:505-5017

Brown GD, Williams DL (2009) $(1,3)-\beta$-Glucans in innate immunity: mammalian systems. In: Bacic A, Fincher GB, Stone BA (eds) Chemistry, biochemistry, and biology of 1-3 $B$ glucans and related polysaccharides. Academic Press, London, pp 579-619
Busse N, Fuchs F, Kraume M, Czermak P (2016) Treatment of enzymeinitiated delignification reaction mixtures with ceramic ultrafiltration membranes: experimental investigations and modeling approach. Sep Sci Technol 51:1546-1565

De Bruijn JPF, Venegas A, Martínez JA, Bórquez R (2003) Ultrafiltration performance of Carbosep membranes for the clarification of apple juice. LWT - Food Sci Technol 36:397-406

Draget KI, Smidsrød O, Skjåk-Bræk G (2005) Alginates from algae. In: Steinbüchel A (ed) Polysaccharides and polyamides in the Food Industry. Wiley-VCH, Weinheim pp 1-30

Gidley MJ, Nishinari K (2009) Physico-chemistry of (1,3)- $\beta$-glucans. In: Bacic A, Fincher GB, Stone BA (eds) Chemistry, biochemistry, and biology of 1-3 $\beta$ glucans and related polysaccharides. Academic Press, London, pp 47-118

Hasselström L, Thomas JB, Nordström J, Cervin G, Nylund GM, Pavia H, Gröndahl F (2020) Socioeconomic prospects of a seaweed bioeconomy in Sweden. Sci Rep 10:1610

Hjelland F, Hanning A, Yang H (2012) Process for isolating fucoidan and laminarin from live, harvested seaweed. USA Patent 2012/0302742

Jard G, Marfaing H, Carrère H, Delgenes JP, Steyer JP, Dumas C (2013) French Brittany macroalgae screening: composition and methane potential for potential alternative sources of energy and products. Biores Technol 144:492-498

Klarzynski O, Plesse B, Joubert JM, Yvin JC, Kopp M, Kloareg B, Fritig B (2000) Linear $\beta-1,3$ glucans are elicitors of defense responses in tobacco. Plant Physiol 124:1027-1037

Martinez-Ferez A, Guadix A, Guadix EM (2006) Recovery of caprine milk oligosaccharides with ceramic membranes. J Memb Sci 276: 23-30

McDonnell P, Figat S, Odoherty JV (2010) The effect of dietary laminarin and fucoidan in the diet of the weanling piglet on performance, selected faecal microbial populations and volatile fatty acid concentrations. Animal 4:579-585

McHugh DJ (2003) A Guide to the Seaweed Industry. Food and Agriculture Organization of the United Nations, Rome

Myklestad SM, Granum E (2009) Biology of $(1,3)$ - $\beta$-glucans and related glucans in protozoans and chromistans. In: Bacic A, Fincher GB, Stone BA (eds) Chemistry, biochemistry, and biology of 1-3 ß glucans and related polysaccharides. Academic Press, London, pp 353 385

Obluchinskaya ED (2008) Comparative chemical composition of the Barents Sea brown algae. Appl Biochem Microbiol 44:305-309

Pawel P (2014) Salinity tolerance and osmoregulatory function of mannitol in Danish ecotype of Saccharina latissima. Roskilde University, Denmark

Porse H, Rudolph B (2017) The seaweed hydrocolloid industry: 2016 updates, requirements, and outlook. J Appl Phycol 29:2187-2200

Rinaudo M (2007) Seaweed Polysaccharides. In: Kamerling H (ed) Comprehensive glycoscience: from chemistry to systems biology. Elsevier, Oxford, pp 691-735

Rinaudo M (2014) Biomaterials based on a natural polysaccharide: alginate. TIP 17:92-96

Ripperger S, Gösele W, Alt C, Loewe T (2013) Filtration, 1. Fundamentals. In: Ullmann's encyclopedia of industrial chemistry. Wiley-VCH Verlag, Weinheim pp 1-38

Schiener P, Black KD, Stanley MS, Green DH (2015) The seasonal variation in the chemical composition of the kelp species Laminaria digitata, Laminaria hyperborea, Saccharina latissima and Alaria esculenta. J Appl Phycol 27:363-373

Sterner M, Edlund U (2016) Multicomponent fractionation of Saccharina latissima brown algae using chelating salt solutions. J Appl Phycol 28:2561-2574

Sterner M, Ribeiro MS, Gröndahl F, Edlund U (2017) Cyclic fractionation process for Saccharina latissima using aqueous chelator and ion exchange resin. J Appl Phycol 29:3175-3189 
Stévant P, Marfaing H, Rustad T, Sandbakken I (2017) Nutritional value of the kelps Alaria esculenta and Saccharina latissima and effects of short-term storage on biomass quality. J Appl Phycol 29:2417-2426

Stone BA (2009) Chemistry of $\beta$-glucans. In: Bacic A, Fincher GB, Stone BA (eds) Chemistry, biochemistry, and biology of 1-3 Beta Glucans and Related Polysaccharides. Academic Press, London, pp 5-46

Thomas JB, Ribeiro MS, Potting J, Cervin G, Nylund GM, Olsson J, Albers E, Undeland I, Pavia H, Gröndahl F (2020) A comparative environmental life cycle assessment of hatchery, cultivation, and preservation of the kelp Saccharina latissima. ICES J Mar Sci:1-17

Vegas R, Moure A, Domínguez H, Parajó JC, Alvarez JR, Luque S (2008) Evaluation of ultra- and nanofiltration for refining soluble products from rice husk xylan. Bioresour Technol 99:5341-5351

Vilg JV, Nylund GM, Werner T, Qvirist L, Mayers JJ, Pavia H, Undeland I, Albers E (2015) Seasonal and spatial variation in biochemical composition of Saccharina latissima during a potential harvesting season for Western Sweden. Bot Mar 58:435-447

Vladisavljević GT, Vukosavljević P, Bukvić B (2003) Permeate flux and fouling resistance in ultrafiltration of depectinized apple juice using ceramic membranes. J Food Eng 60:241-247

Yvin JC, Levasseur F, Amin-Gendy C, Tran Thanh KN, Patier P, Rochas C, Lienart Y, Cloarec B (1998) Laminarin as a seed germination and plant growth accelerator. USA Patent 1998/5750472

Yvin JC, Levasseur F, Hud'Homme F (1999) Use of laminarin and oligosaccharides derived therefrom in cosmetics and for preparing a skin treatment drug. USA Patent 1999/5980916

Žabková M (2006) Clean technologies for the purification of wastewaters: adsorptive parametric pumping. Thesis, University of Porto

Publisher's note Springer Nature remains neutral with regard to jurisdictional claims in published maps and institutional affiliations. 